TAO, Vol. 15, No. 3, 329-360, September 2004

\title{
ULF Geomagnetic Changes Associated with Large Earthquakes
}

\author{
Katsumi Hattori ${ }^{1}$, \\ (Manuscript received 4 April 2004, in final form 28 June 2004)
}

\begin{abstract}
Despite its extreme importance and years of effort, practical short-term earthquake prediction still remains to be seen. However, research in earthquake-related electromagnetic phenomena have recently shown that such phenomena make for a promising candidate for short-term earthquake prediction. There is a good deal of accumulated evidence of precursory signatures in a wide frequency range (DC-VHF). ULF geomagnetic change is one of the most promising phenomena and it suggests that short-term prediction is realizable. This report first reviews earlier observational facts and presents the latest results in detection of ULF emissions by means of sophisticated signal processing. Finally, we discuss the possible generation and propagation mechanism of earthquake-related ULF signals.
\end{abstract}

(Key words: Short-term earthquake prediction, Earthquake-related electromagnetic phenomena, ULF geomagnetic change, ULF emissions, Sophisticated signal processing)

\section{INTRODUCTION}

Short-term earthquake prediction seems difficult by means of conventional elastic measurements. Therefore, new approaches and/or observable phenomena to assist in prediction are highly desirable. Electromagnetic phenomena are now considered a promising candidate for short-term prediction of large earthquakes (e.g., Hayakawa and Fujinawa 1994, Hayakawa 1999, Hayakawa and Molchanov 2002). Research stimulated by Japan's two earthquake Frontier Projects [International Frontier Research on Earthquakes by the Institute of Physical and Chemical Research, hereafter known as RIKEN (Uyeda 2003) and Earthquake Remote Sensing Frontier by the National Space Development Agency of Japan, hereafter known as NASDA (Hayakawa 2001)], has led to an accumulation of observational reports on earthquake-related electromagnetic studies in a very wide frequency range all over the world.

\footnotetext{
${ }^{1}$ Marine Biosystems Research Center, Chiba University, Inage, Chiba, Japan

* Corresponding author address: Prof. Katsumi Hattori, Marine Biosystems Research Center, Chiba University, Inage, Chiba, Japan; E-mail: hattori@earth.s.chiba-u.ac.jp
} 
Measurements of electromagnetic phenomena can be classified into three types: (1) passive ground-based observation for lithospheric emissions in a wide frequency range from DC to VHF (Fraser-Smith et al. 1990, Bernardi et al. 1991, Molchanov et al. 1992, Kopytenko et al. 1993, 1994, Lighthill 1996, Hayakawa et al. 1996a, Kawate et al. 1998), (2) ground-based observation with the use of transmitter signals as active monitoring of seismo-atmospheric and seismo-ionospheric perturbations (Gokhberg et al. 1982, Gufeld et al. 1994, Hayakawa et al. 1996b, Molchanov and Hayakawa 1998), (3) satellite observations of plasma perturbations and radio emissions associated with earthquakes in the upper atmosphere (Galperin and Hayakawa 1996, Parrot 1999).

This paper deals with ULF anomalies associated with large earthquakes. ULF phenomena provide a promising tool for earthquake-related electromagnetic studies as such emissions come from the crust of the source region. There has been a good deal of accumulated and convincing evidence of ULF magnetic signatures before large earthquakes as evidenced by the following studies: Fraser-Smith et al. (1990), Kopytenko et al. (1992), Molchanov et al. (1992), Hayakawa et al. (1996a), Kawate et al. (1998), Hayakawa et al. (2000), Uyeda et al. (2002), Gotoh et al. (2002), Hattori et al. (2002).

Similar electromagnetic phenomena are associated with volcanic activity. Since source regions are well known for their volcanic activity, observation is easier than in seismic cases. Electromagnetic phenomena associated with volcanic activities have been summarized in the works of Johnston (1997) and Zlotnicki (2003).

Although, before the 1989 Loma Prieta earthquake in California, geomagnetic anomalous changes associated with large earthquakes had been reported, these mainly dealt with anomalous change in transfer functions before earthquakes and pointed to the possibility of change in underground electrical structure.

The aim of this paper is to summarize ULF geomagnetic phenomena associated with large earthquakes, based mainly on historical experimental facts that have occurred post Johnston's review (1997). In particular, the latest results from Japan will be reported. In addition, possible mechanisms and propagations are discussed. Finally, future tasks will be proposed for further research in this field.

\section{ULF MAGNETIC CHANGES THAT MIGHT BE DUE TO ELECTRICAL STRUCTURE CHANGES UNDER THE GROUND}

It is well known that a linear relation exists among three components of geomagnetic field variations observed on the ground:

$$
\Delta Z(\omega)=A(\omega) \cdot \Delta X(\omega)+B(\omega) \cdot \Delta Y(\omega)
$$

where $\Delta X(\omega), \Delta Y(\omega), \Delta Z(\omega)$ and are geographic NS, EW, and vertical components of geomagnetic variations, respectively. These are mathematically complex Fourier components (e.g., Rikitake and Honkura 1985). This relationship is interpreted as a linear system that has two inputs of and $\Delta X(\omega)$ and $\Delta Y(\omega)$ an output of $\Delta Z(\omega)$. The coefficients $A(\omega)$ and $B(\omega)$ 
are considered to be invariant at a certain duration and specific to a given station, and are frequency-dependent complex transfer functions. The transfer functions have information on the electric conductivity under the ground at a given station. Studies using transfer functions have usually been conducted for anomalies of the vertical field component. It is called CA (Conductivity Anomaly) and the induction arrow or the Perkinson vector is used for description of CA, of which length and direction indicate the magnitude of magnetic anomaly and source direction, respectively (e.g., Rikitake and Honkura 1985).

$$
\begin{aligned}
& A m p(\omega)=\sqrt{A_{\mathrm{Re}}^{2}(\omega)+B_{\mathrm{Re}}^{2}(\omega)}, \\
& \operatorname{Azim}(\omega)=\tan ^{-1}\left[A_{\mathrm{Re}}(\omega) / B_{\mathrm{Re}}(\omega)\right] .
\end{aligned}
$$

Generally, the aim of CA study is to clarify the distribution of electric conductivity in the crust and mantle. It means the conductivity is defined as an invariant property in time. Actually, time average with intense external field is used to determine CA. But, if the crustal activity gives rise to some perturbation on the conductivity, the transfer function is expected to change. Yanagihara (1972) reported that $\Delta Z / \Delta H$ (the ratio of vertical and horizontal components of short-period geomagnetic fields) at Kakioka showed an anomalous change before the Kanto earthquake in 1923 as shown in Fig. 1. Furthermore, Yanagihara and Nagano (1976) indicated that there is a good correlation between the temporal variation of the transfer function and earthquakes with $M>5$ that occurred around the Kakioka station. On the other hand, Shiraki (1980) showed no apparent correlation between the transfer function change and the local seismisity around the Kakioka station from January 1976 to April 1979.

In China, a similar approach has been made. They computed the induction arrow and showed that the direction of the arrow pointed to a large earthquake in the future at the source region (Zhen, Xiaoping, private communication).

As described above, anomalous short-period geomagnetic variation is usually indicated by an anomalous vertical field $(\Delta Z)$ in Eq.(1). The time-dependence of the transfer function associated with earthquakes, estimated by using a reference station which is located far from the site and in the aseismic area, may give us some important information. The formulation of this approach is as follows:

$$
\left(\begin{array}{l}
\Delta X_{s}(\omega) \\
\Delta Y_{s}(\omega) \\
\Delta Z_{s}(\omega)
\end{array}\right)=\left(\begin{array}{c}
T_{x x}(\omega) T_{x y}(\omega) \\
T_{y x}(\omega) T_{y y}(\omega) \\
T_{z x}(\omega) T_{z y}(\omega)
\end{array}\right) \cdot\left(\begin{array}{c}
\Delta X_{r}(\omega) \\
\Delta Y_{r}(\omega)
\end{array}\right),
$$

where suffix $r$ denotes the reference station and $\mathrm{T}_{\mathrm{ii}}$ is the interstation transfer function. In this equation, both vertical and horizontal components are shown as a linear combination by using the interstation transfer functions (ISTF) (e.g., Schmucker 1970). Investigation on the timedependence of ISTF associated with earthquakes has been made by Honkura and Beamish. 
Honkura investigated the ISTF associated with 1978 Izu-Oshima-Kinkai Earthquake (M7.0). The results showed that the transfer function seemed to have been enhanced prior to the earthquake even under noisy conditions (Honkura and Koyama 1978; Honkura 1979). Beamish (1982) reported the anomalous change of horizontal ISTF preceding the 1979 Carlisle earthquake as shown in Fig. 2.

The observed anomalous changes of transfer functions can be interpreted as the appearance of a conductive area in the focal region preceding an earthquake. An increase of electric conductivity at the focal area is likely due to the dilatancy-diffusion (Scholz et al. 1973). That is, the flow of underground water into the focal region plays an important role. A conventional transfer function approach may be useful for mid-term earthquake prediction.

As for the 1972 Miyagiken-oki earthquake (M7.4) the ratio between observed vertical component and the theoretically calculated one shows $20 \%$ enhanced values about 2 months prior to the earthquake (Kato et al. 1980, see Fig. 3). They considered this to be based on anomalous conductivity change in the source region; however, the values obtained required a huge change in conductivity, and their results were considered questionable at that time. There is a possibility that they caught the ULF emissions as described in the next section.
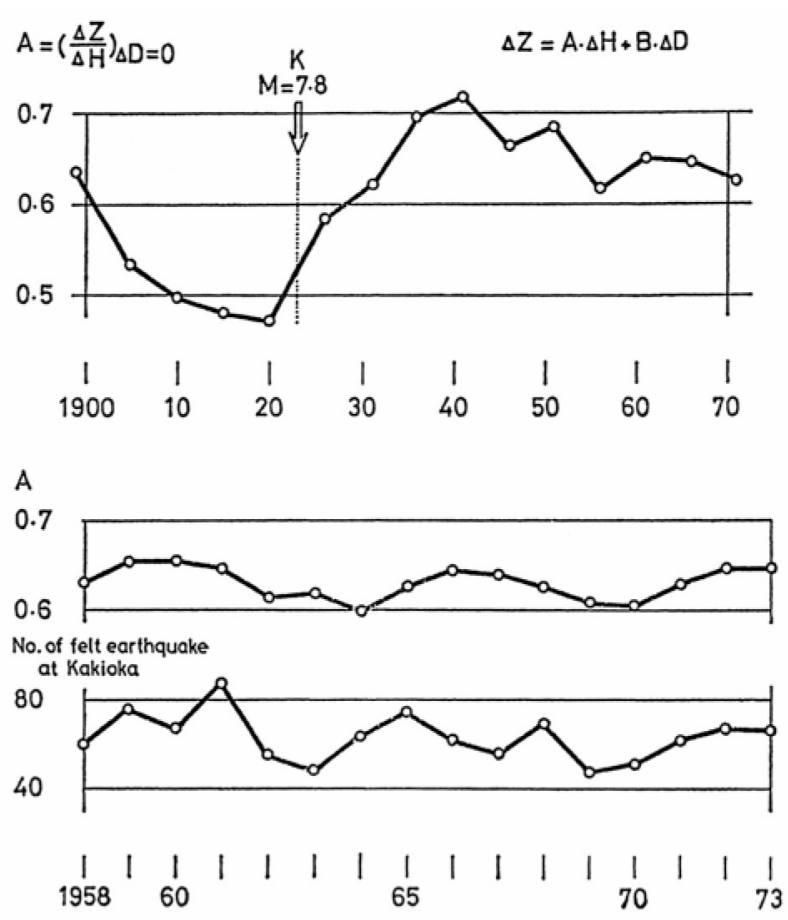

Fig. 1. Transfer function variation of A value at Tokyo (1897 - 1912) and Kakioka (1913-1973). The day of the 1923 Kanto earthquake is indicated by an arrow. The number of felt earthquakes is also shown in the lower panel (Yanagihara and Nagata 1976). 
(a)

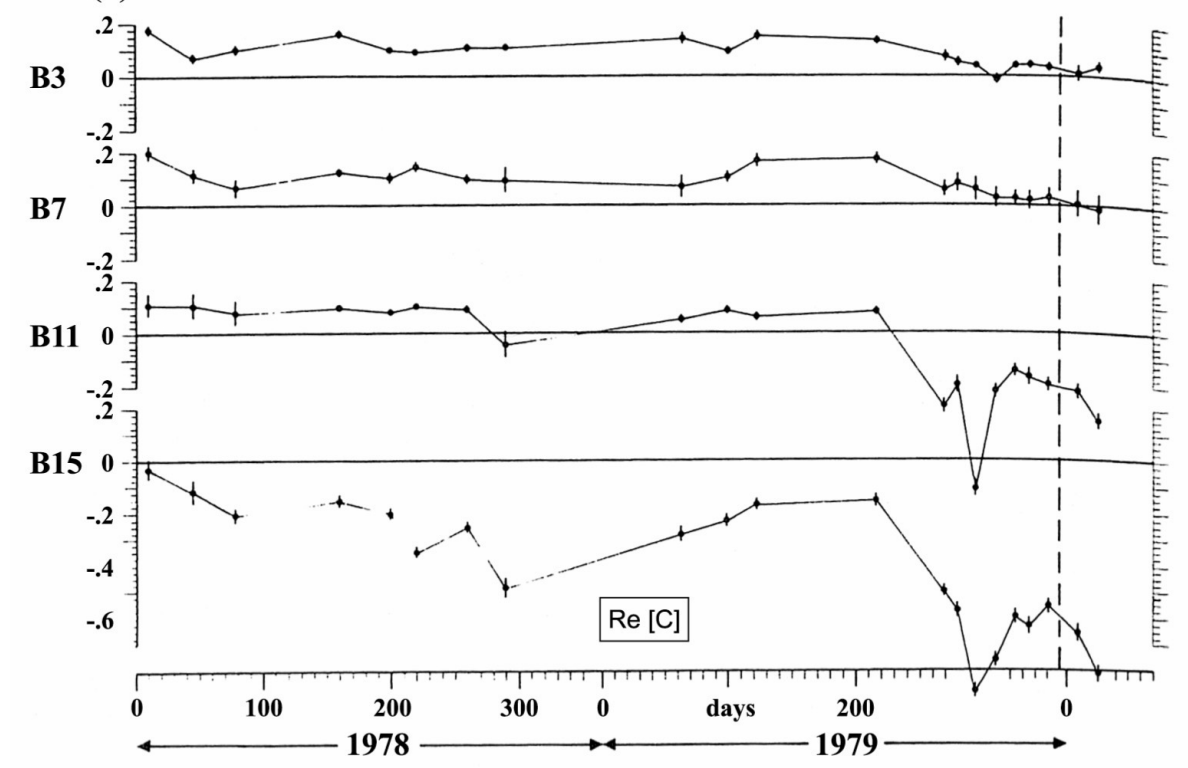

(b)

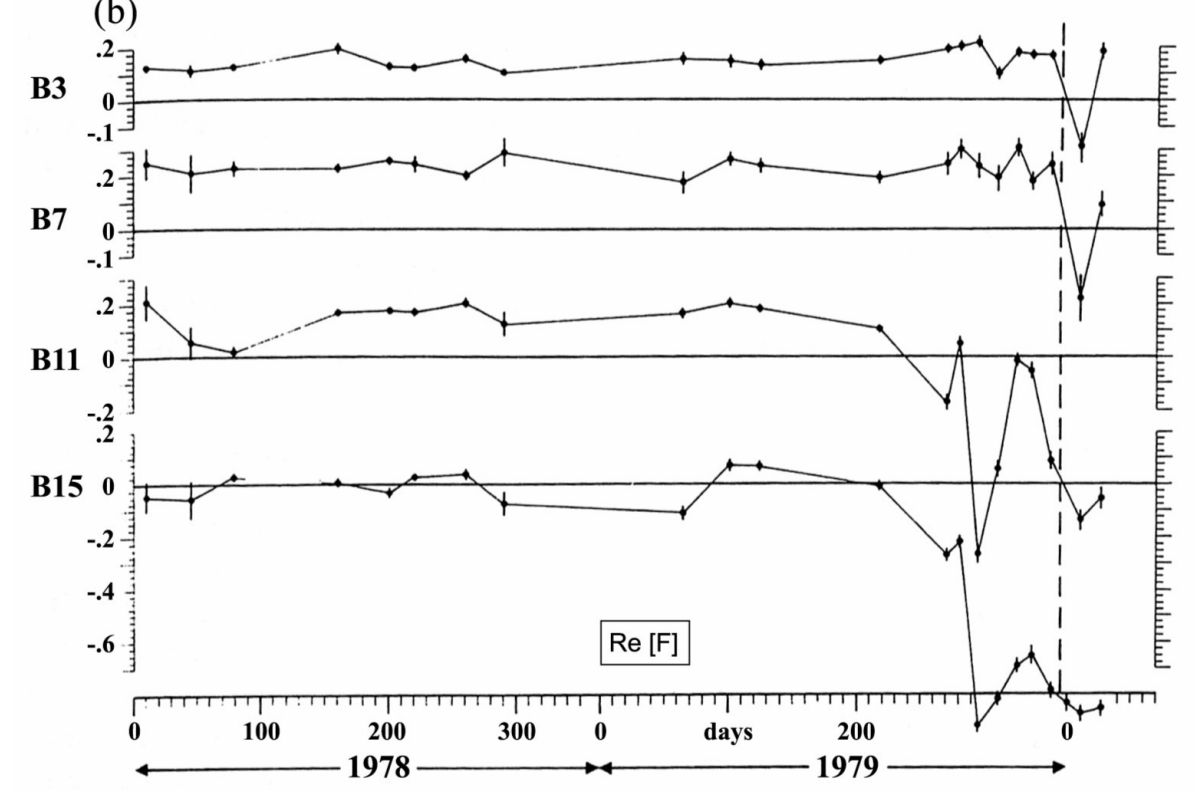

Fig. 2. The variation of interstation transfer functions $\mathrm{C}$ and $\mathrm{F}$ values of real part during 1978 and 1979. B3, B7, B11, and B15 show the period range of 4000 - $2000 \mathrm{sec}, 1000$ - $600 \mathrm{sec}, 250$ - $150 \mathrm{sec}$, and B15: 70 - $50 \mathrm{sec}$, respectively. The vertical broken line indicates the 1979 Carlisle earthquake (Beamish 1982). 


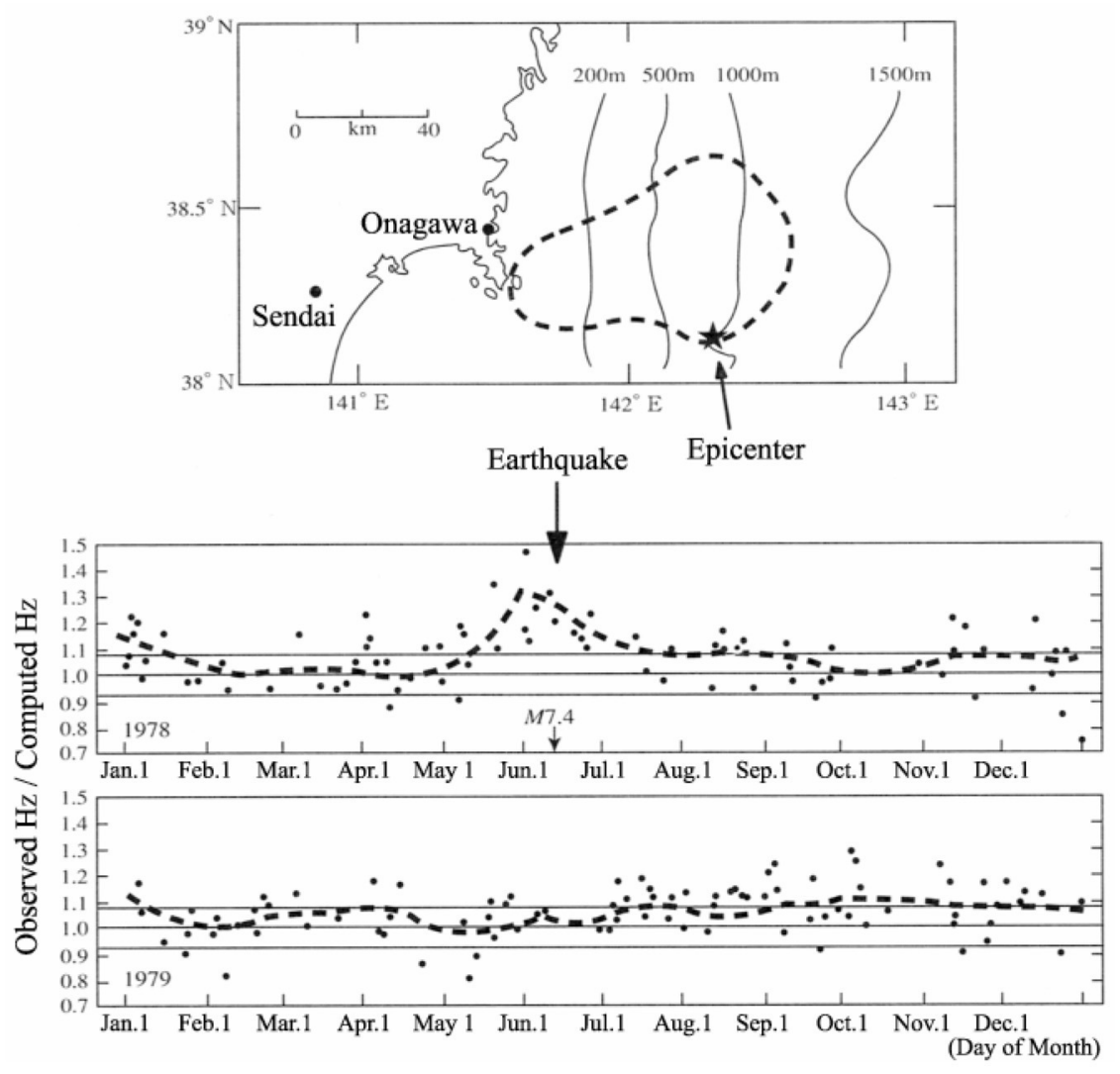

Fig. 3. Anomalous geomagnetic change associated with the 1978 MiyagikenOki earthquake (Kato et al. 1984). Top panel indicates the focal region and the lower panel shows the ratio between computed and observed vertical component in 1978 and 1979. The day of the earthquake is marked by an arrow.

\section{ULF GEOMAGNETIC CHANGES DUE TO ULF EMISSIONS}

In the 1990's the idea that ULF emissions were associated with large earthquakes became apparent. This idea opened up possibilities for short-term prediction. Table 1 shows results from three pioneering works. ULF emission associated with large earthquakes was almost simultaneously discovered in Russia and America. The first recording of earthquake-related ULF emission was carried out by a Russian group (Kopytenko 1990, 1993). They reported anomalous ULF emissions preceding the 1988 Spitak earthquake (M6.9). The second was a significant observation associated with the 1989 Loma Prieta earthquake (Fraser-Smith et al. 1990, Bernardy et al. 1991). Here, the epicentral distance was small and the focal depth very shallow resulting in the simple amplitude record showing an apparent anomalous change. Figure 4 shows the variation of magnetic intensity at $0.01 \mathrm{~Hz}$ (100 second period) band, which 
Table 1. Pioneering works on the ULF emission prior to large earthquakes.

\begin{tabular}{|c|c|c|c|}
\hline & $\begin{array}{c}\text { Spitak EQ } \\
\text { (Kopytenko et a1, PEPI } \\
77,85,1993)\end{array}$ & $\begin{array}{c}\text { Loma Prieta EQ } \\
\text { (Fraser-Smith et a1., GRL, } \\
17,1465,1990)\end{array}$ & $\begin{array}{c}\text { Guam EQ } \\
\text { (Hayakawa et al., GRL, 23, } \\
241,1996)\end{array}$ \\
\hline Day of EQ & Dec. 8, 1988 & Oct. 18, 1989 & Aug. 8, 1993 \\
\hline Magnitude & 6.9 & 7.1 & 8.0 \\
\hline Depth & $6 \mathrm{~km}$ & $15 \mathrm{~km}$ & $60 \mathrm{~km}$ \\
\hline Distance & $129 \mathrm{~km}$ & $7 \mathrm{~km}$ & $65 \mathrm{~km}$ \\
\hline Components & 3 components & H component & 3 components \\
\hline Frequency range & $0.0005-5 \mathrm{~Hz}$ & $0.01-10 \mathrm{~Hz}$ & $-0.5 \mathrm{~Hz}$ \\
\hline Lead Time & $\begin{array}{c}\text { Intensity Anomaly 3-4 } \\
\text { days before EQ }\end{array}$ & $\begin{array}{c}\text { Intensity Anomaly 12 days } \\
\text { before EQ }\end{array}$ & $\begin{array}{c}\text { Polarization(SZ/SH) } \\
\text { Anomaly } 1 \mathrm{month} \text { before } \\
\text { EQ }\end{array}$ \\
\hline $\begin{array}{c}\text { Characteristics } \\
\text { (pre-seismic) }\end{array}$ & $\begin{array}{c}\text { Sudden increase } \\
4 \text { hours before EQ }\end{array}$ & $\begin{array}{c}\text { Sudden increase } \\
3 \text { hours before EQ }\end{array}$ & $\begin{array}{c}\text { Maximum level of } \\
\text { polarization(SZ/SH) }\end{array}$ \\
\hline $\begin{array}{c}\text { Characteristics } \\
\text { (post-seismic) }\end{array}$ & $\begin{array}{c}\text { Disappear 1 month after } \\
\text { EQ }\end{array}$ & $\begin{array}{c}\text { Disappear some months } \\
\text { after EQ }\end{array}$ & $\begin{array}{c}1 \mathrm{month} \text { after EQ, } \\
\text { polarization came to } \\
\text { normal level }\end{array}$ \\
\hline
\end{tabular}

exhibits the first enhancement from 2 weeks to 1 week prior to the earthquake, followed by a quiet period, and a consequent sharp increase a few hours before the earthquake occurred. The disturbance lasted about 3 months and then the intensity level recovered to its original level depicted at the beginning of Fig. 4. The observations had been carried out for more than ten years and this kind of strange behavior had not been observed previously. They examined various possibilities and finally concluded that the anomaly was likely related to the earthquake.

A third important event was the 1993 Guam earthquake (M 8.0) (Hayakawa et al. 1996a). Hayakawa et al. (1996) proposed a new method for detecting earthquake-related ULF emissions with the use of simultaneous recording of orthogonal three geomagnetic field components. They demonstrated that the use of the ratio $\left(\mathrm{S}_{\mathrm{Z}} / \mathrm{S}_{\mathrm{H}}\right)$, called polarization, is of essential importance in discriminating the seismic emissions from other signals such as magnetospheric variations. Here $S_{Z}$ and $S_{H}$ indicate the spectral intensities of vertical and horizontal components. They found anomalous increase in polarization preceding the earthquake as shown in Fig. 5. Here, the epicentral distance is about $65 \mathrm{~km}$.

\section{RECENT ATTEMPTS AT ULF GEOMETRIC STUDIES PRECEDING LARGE EARTHQUAKES}

In view of the observational facts described in the previous section, the accumulation of convincing events that indicate the apparent presence of ULF emissions associated with earthquakes have been considered highly desirable. For this reason, related projects have been initiated in several countries. 


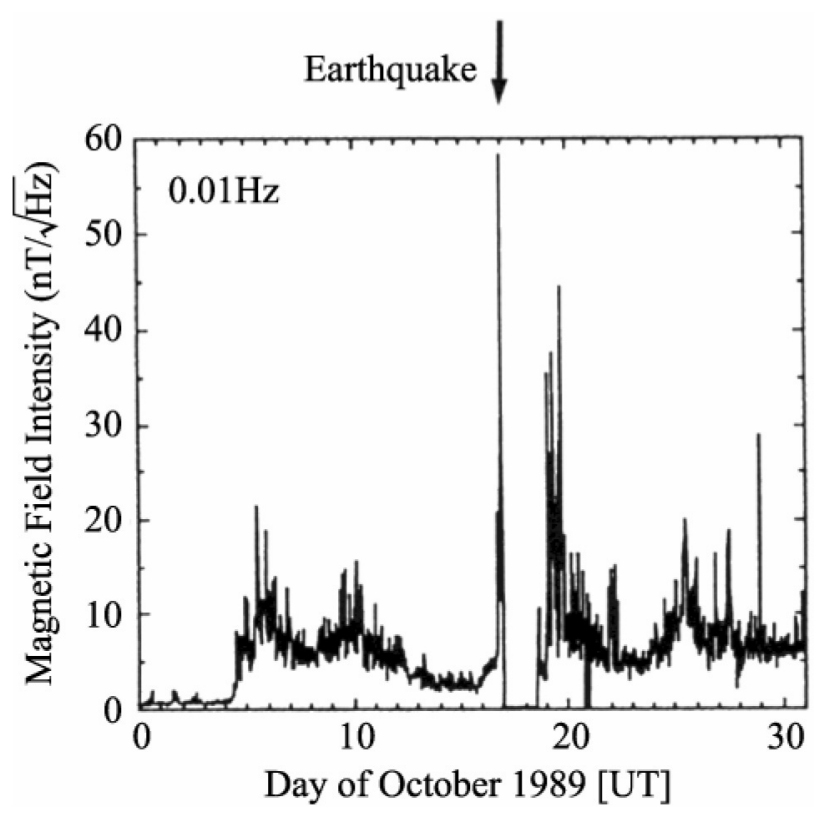

Fig. 4. Anomalous geomagnetic change associated with the 1989 Loma Prieta earthquake (after Fraser-Smith et al. 1990).

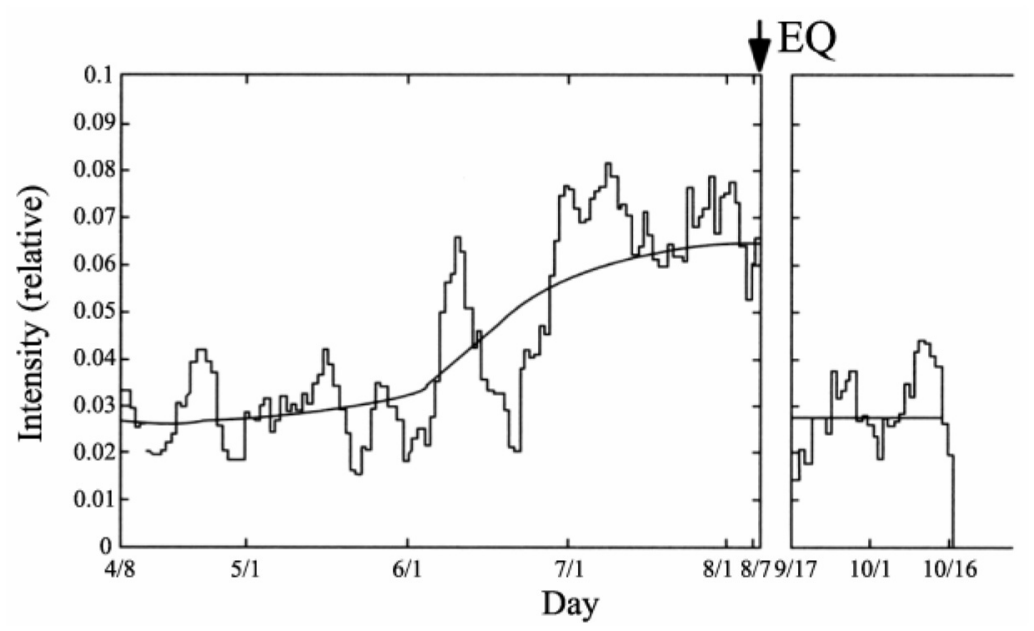

Fig. 5. Anomalous geomagnetic change associated with the 1993 Guam earthquake (after Hayakawa et al. 1996). 
In Japan, RIKEN-NASDA's project struggled with the problem after the Kobe earthquake in 1995. It is important to predict earthquakes with $M \geq 6$ in highly populated regions to mitigate disasters. Therefore, it was decided that a network of sensitive ULF magnetometers with high sampling rates should be installed through out Kanto (Tokyo) - Tokai area with inter-sensor distances of about $100 \mathrm{~km}$. The clock system at each station is GPS controlled. Figure 6 illustrates the network. Kakioka station is operated by JMA (Japan Meteorological Agency). A small L-shaped array has been set with inter-station distance of $5 \mathrm{~km}$ in northsouth and east-west directions in each of the western part of Izu Peninsula and the southern part of Boso Peninsula. At most of the ULF stations two horizontal electric fields are also measured simultaneously (Hattori et al. 2004a).

Similar ULF magnetometer networks have been installed in Kamchatka, Russia (Uyeda et al. 2002; Gladychev et al. 2002), Taiwan (Hattori et al. 2002), and Greece (Makris et al. 2003) where a good deal of effort is being expended in ULF magnetic observation.

The following describes recent achievements in ULF emissions studies associated with earthquakes. It should be emphasized here that pre-seismic anomalies are generally too weak to be recognized by looking sat raw data and some elaborate data processing is required. It is found that several methods, including polarization analysis, principal component analysis and direction finding techniques, are quite useful for this purpose and that a frequency range of $0.01 \mathrm{~Hz}$ is useful for monitoring crustal activity.

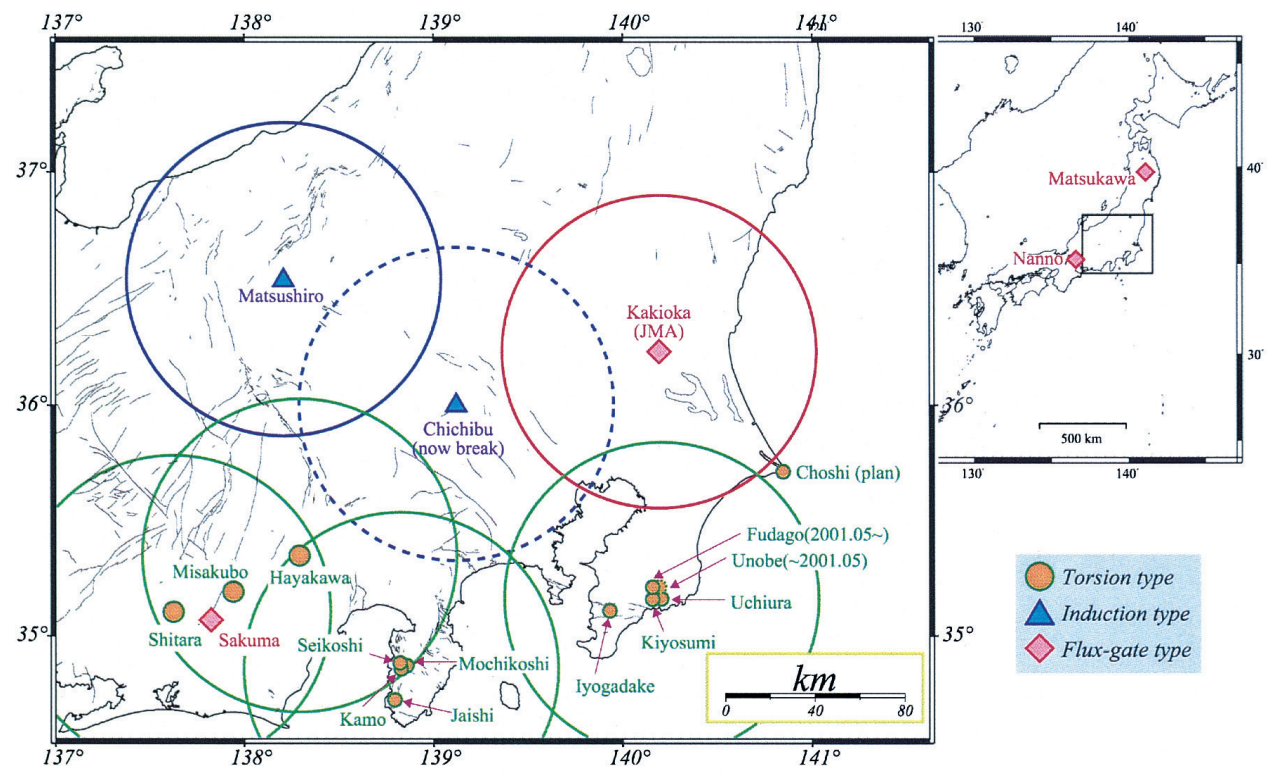

Fig. 6. ULF electromagnetic network in the central Japan (after Hattori et al. 2004a). 


\subsection{Intensity Measurement}

The intensity at different frequencies can be monitored with an adequate filter. However, investigation of amplitude seems to be only effective when the observation site is located close to the epicenter such as in the case of the Loma Prieta earthquake. No similar report has been reported after the Loma Prieta earthquake.

\subsection{Polarization Analysis}

As described in the previous section (the 1993 Guam earthquake), polarization analysis is

Table 2. Summary of polarization analysis.

\begin{tabular}{|c|c|c|c|c|c|c|c|c|}
\hline & $\begin{array}{l}\text { Kagoshimaken } \\
\text {-Hokuscibu } \\
\text { EQ }\end{array}$ & $\begin{array}{l}\text { Iwateken-Nairi } \\
\text { kuhokubu } \mathrm{EQ}\end{array}$ & Izu EQ Swarm & $\begin{array}{c}\text { EQ near } \\
\text { Matshshiro }\end{array}$ & $\begin{array}{c}\text { Biak EQ } \\
\text { (Indonesia) }\end{array}$ & $\begin{array}{l}\text { Chi-Chi EQ } \\
\text { (Taiwan) }\end{array}$ & $\begin{array}{c}\text { Izu Islands EQ } \\
\text { swarm }\end{array}$ & EQ at Boso \\
\hline Day of EQ & $\begin{array}{l}19970326 \\
19970513 \\
\end{array}$ & 19980903 & $\begin{array}{c}199804-05 \\
19980503 \\
\end{array}$ & 19980701 & 19960217 & 19990921 & $200006-09$ & 20030921 \\
\hline $\begin{array}{l}\text { Magnitude } \\
\text { (JMA) }\end{array}$ & $\begin{array}{l}6.5 \\
6.3\end{array}$ & 6.1 & $\begin{array}{c}\text { Max5.7 } \\
(19980503)\end{array}$ & 4.5 & $8.2(\mathrm{Mw})$ & $7.7(\mathrm{Mw})$ & $\begin{array}{l}6.4(\mathrm{Jul} .1) \\
6.1(\mathrm{Jul} .9) \\
6.3(\mathrm{Jul} .15) \\
\end{array}$ & 5.6 \\
\hline Depth & $20 \mathrm{~km}$ & $10 \mathrm{~km}$ & $10 \mathrm{~km}$ & $20 \mathrm{~km}$ & $20 \mathrm{~km}$ & $10 \mathrm{~km}$ & shallow & \\
\hline Distance & $65 \mathrm{~km}$ & $15 \mathrm{~km}$ & $30 \mathrm{~km}$ & $25 \mathrm{~km}$ & $100 \mathrm{~km}$ & $135 \mathrm{~km}$ & $70-150 \mathrm{~km}$ & \\
\hline $\begin{array}{c}\text { Magnactomete } \\
\mathrm{r}\end{array}$ & $\begin{array}{l}\text { Fluxgate } \\
1 \text { Hz samp. }\end{array}$ & $\begin{array}{l}\text { Fluxgate } \\
\text { I Hz samp. }\end{array}$ & $\begin{array}{c}\text { Torsion } \\
50 \mathrm{~Hz} \text { samp }\end{array}$ & $\begin{array}{c}\text { Induction } \\
85 \mathrm{~Hz} \text { samp }\end{array}$ & $\begin{array}{l}\text { Fluxgate } \\
1 \text { Ilz samp. }\end{array}$ & $\begin{array}{l}\text { Fluxgate } \\
1 \mathrm{llz} \text { samp. }\end{array}$ & $\begin{array}{c}\text { Torsion } \\
50 \mathrm{llz} \text { samp }\end{array}$ & $\begin{array}{c}\text { Torsion } \\
50 \mathrm{~Hz} \text { samp }\end{array}$ \\
\hline $\begin{array}{c}\text { Frequency } \\
\text { range of } \\
\text { anomaly }\end{array}$ & $\begin{array}{c}0.01- \\
0.03 \mathrm{~Hz}\end{array}$ & $\begin{array}{l}0.005- \\
0.01 \mathrm{~Hz}\end{array}$ & $\begin{array}{c}0.01- \\
0.03 \mathrm{~Hz}\end{array}$ & $\begin{array}{c}0.01- \\
0.03 \mathrm{~Hz}\end{array}$ & $\begin{array}{c}0.01- \\
0.03 \mathrm{~Hz}\end{array}$ & $0.01 \mathrm{H} x$ & $\begin{array}{l}0.01- \\
01 \mathrm{~Hz}\end{array}$ & $0.01 \mathrm{~Hz}$ \\
\hline $\begin{array}{c}\text { Characteristic } \\
\text { s } \\
\text { (Intensity) }\end{array}$ & $\begin{array}{l}\text { Intensified a } \\
\text { few weeks } \\
\text { before the } 1^{\text {st }} \\
\text { EQ in } Z \text { comp. }\end{array}$ & & & $\begin{array}{l}\text { Intensified one } \\
\text { day before the } \\
\text { EQ in } \\
\text { horizontal } \\
\text { comp. }\end{array}$ & & & $\begin{array}{l}\text { PCA: } \$ .3 \\
\text { intensified the } \\
\text { day or a lew } \\
\text { days prior to } \\
\text { M6-EQs }\end{array}$ & \\
\hline $\begin{array}{l}\text { Characteristic } \\
\mathrm{s} \\
\text { (Polarization) }\end{array}$ & $\begin{array}{l}\text { Increase a few } \\
\text { weeks before } \\
\text { the } 1^{\text {tt }} \mathrm{EQ} \text {. } \\
\text { The } 1^{\text {st }} \mathrm{EQ} \\
\text { occurred at the } \\
\text { decreasing } \\
\text { stage of } \\
\text { polarization }\end{array}$ & $\begin{array}{l}\text { Increase } 16 \\
\text { days before the } \\
\text { EQ. } \\
\text { The } F, Q \\
\text { occurred at the } \\
\text { decreasing } \\
\text { stage of } \\
\text { polarization }\end{array}$ & $\begin{array}{l}\text { Increase a few } \\
\text { weeks before } \\
\text { the } 1^{\text {st }} \text { EQ. } \\
\text { The Swarm } \\
\text { occurred at the } \\
\text { decreasing } \\
\text { stage of } \\
\text { polarization }\end{array}$ & $\begin{array}{l}\text { Inctease } 2 \\
\text { weeks before } \\
\text { the } \mathrm{EQ} \text {. }\end{array}$ & $\begin{array}{l}\text { Increase a few } \\
\text { months before } \\
\text { the EQ. }\end{array}$ & $\begin{array}{l}\text { Increase a few } \\
\text { month before } \\
\text { the EQ. }\end{array}$ & $\begin{array}{l}\text { Not so } \\
\text { apparent }\end{array}$ & $\begin{array}{l}\text { Increase } 3.4 \\
\text { weeks before } \\
\text { the EQ. } \\
\text { The EQ } \\
\text { occurred after } \\
\text { recovering the } \\
\text { polarization } \\
\text { level. }\end{array}$ \\
\hline $\begin{array}{l}\text { Solar Activity } \\
\text { before the } \mathrm{EQ}\end{array}$ & Quiet & Quiel & $\begin{array}{l}\text { Aclive (during } \\
\text { May } 1-7 \text { ) }\end{array}$ & Quiei & Quiet & Quier & $\begin{array}{l}\text { Active (afler } \\
\text { July 15) }\end{array}$ & Quiet \\
\hline $\begin{array}{c}\text { Other } \\
\text { Anomalies }\end{array}$ & & $\begin{array}{l}\text {-DC electric } \\
\text { field dnomaly } \\
19980820\end{array}$ & & $\begin{array}{l}\text {-Acoustic } \\
\text { emission } \\
\text { anomaly } \\
\text { (Intensified } 12 \\
\text { hours before } \\
\text { the EQ) }\end{array}$ & & & $\begin{array}{l}\text {-Direction } \\
\text { Finding } \\
\text { Analysis, } \\
\text {-Fractal } \\
\text { Analysis } \\
\text {-DC electric } \\
\text { field anomaly } \\
\text { at } \\
\text { Nijima(2004- } \\
07)\end{array}$ & \\
\hline
\end{tabular}


useful for discrimination of earthquake-related ULF emissions from other noise. In data analysis, we have confirmed the existence of ULF changes before earthquakes (EQs hereafter) mainly through the use of the polarization $\left(\mathrm{S}_{\mathrm{Z}} / \mathrm{S}_{\mathrm{H}}\right)$. Table 2 shows a summary of polarization analysis. Some typical results are described in what follows.

\subsubsection{Kagoshimaken-Hokuseibu Earthquakes M6.5 EQ1997/03/26 \& M6.3 EQ1997/05/13}

Two moderately large earthquakes occurred at 17h31m L.T. on 26 March, 1997 (U.T. = L.T. - 9hours), and 14 h $38 \mathrm{~m}$ (L.T.) on 13 May, 1997. Their epicenters had geographic coordinates of $\left(32.0^{\circ} \mathrm{N}, 130.3^{\circ} \mathrm{E}\right)$ and $\left(31.9^{\circ} \mathrm{N}, 130.3^{\circ} \mathrm{E}\right)$, respectively. A fluxgate type magnetometer measuring 3 components of the geomagnetic field with a $\mathrm{lHz}$ sampling rate, was in operation at Tarumizu Station $\left(31.48^{\circ} \mathrm{N}, 130.72^{\circ} \mathrm{E}\right)$, which belongs to Nagoya University. The distances between the observatory and epicenters were about $60 \mathrm{~km}$. The geographical relationship between the ULF magnetic station and epicenters of the EQs is shown in Fig. 7. The ULF instrument is composed of three ring core type fluxgate magnetometers [H (NS), D (EW), and $\mathrm{Z}$ (vertical) component] and the waveform data were recorded. Details of the magnetometer

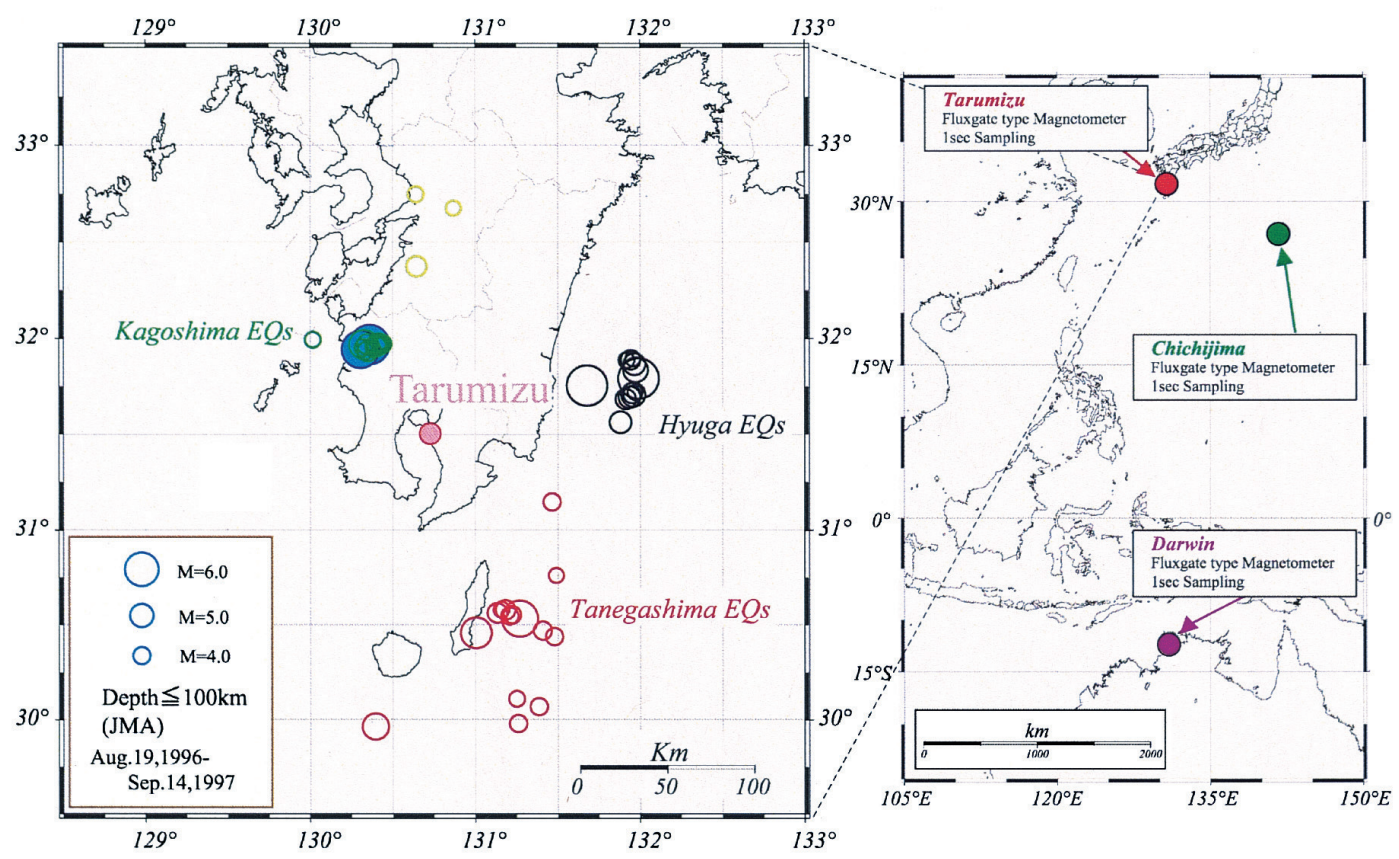

Fig. 7. The 1997 Kagoshimaken-Hokuseibu earthquake and the nearest and remote geomagnetic stations. 


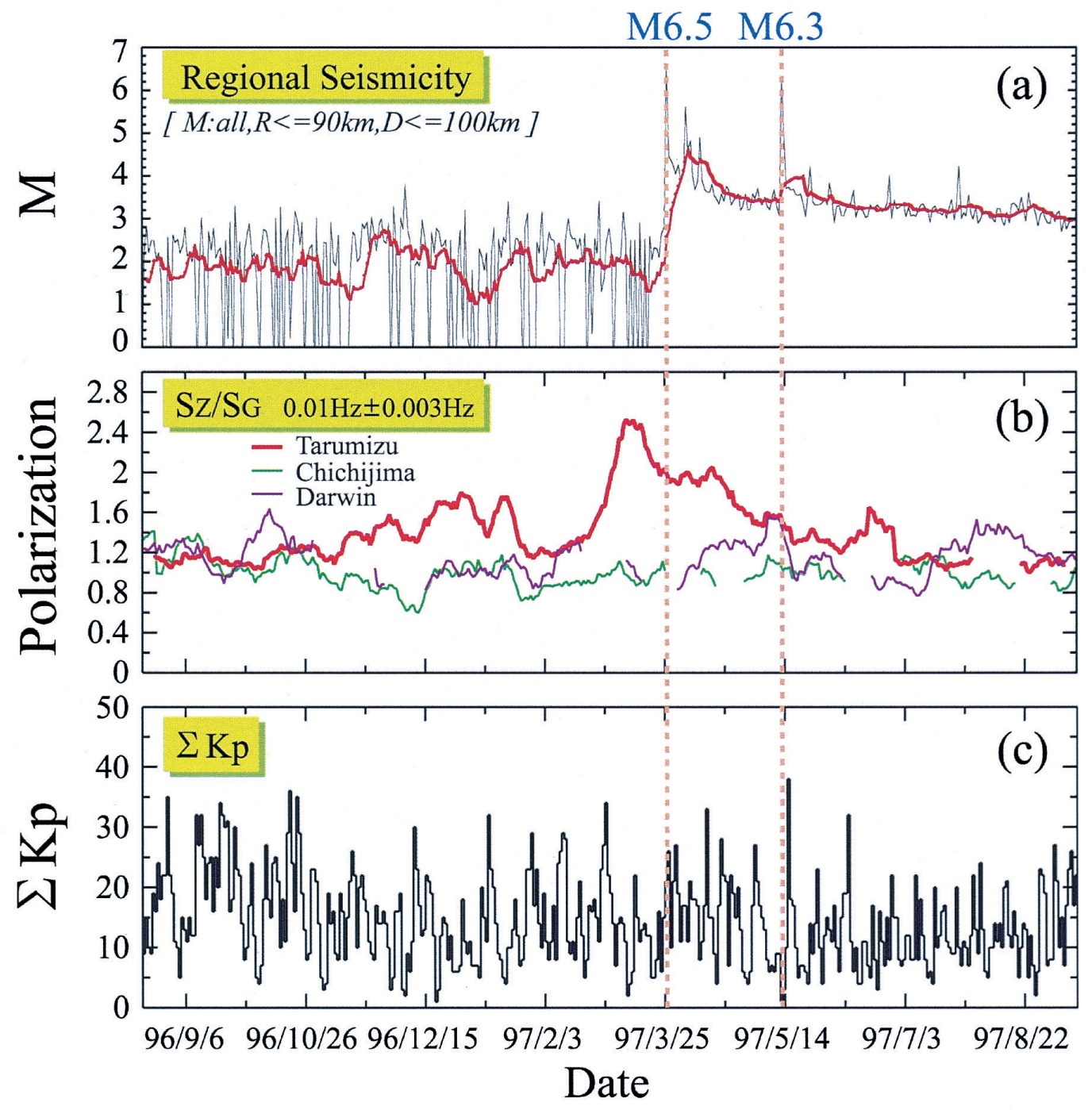

Fig. 8. The geomagnetic anomalous change associated with the KagoshimakenHokuseibu earthquake. (a) The variations of polarization $S_{G} / S_{Z}$ at $0.01 \mathrm{~Hz}$ band, (b) regional daily sum of seismicity in terms of magnitude and (c) $\sum \mathrm{Kp}$. The variation of 10 days backward running mean of daily values is plotted for polarization As for the seismicity, the thin and the thick lines show the daily variation of the regional seismicity and variation of 10 day backward running mean of the daily values (after Hattori et al. 2002). 
system is reported by Yumoto et a1. (1992). These EQs occurred in northwestern Kagoshima Prefecture (Fig. 7). Figure 8 shows the time change of released seismic energy in terms of $\mathrm{M}$ and a 10 day backward running average of polarization $\left(\mathrm{S}_{\mathrm{Z}} / \mathrm{S}_{\mathrm{H}}\right.$ in $0.01 \mathrm{~Hz}$ band) of night time ULF magnetic data at Tarumizu $(\mathrm{r} \sim 60 \mathrm{~km}$, Fig. 7). It is clearly observed that the polarization showed a remarkable pre-seismic enhancement. Similar curves for Chichijima Island in the Bonin Islands $1200 \mathrm{~km}$ away from Darwin, Australia (geomagnetic conjugate point to Tarumizu) did not exhibit such an enhancement, supporting that the change at Tarumizu was associated with the Kagoshima EQs (Hattori et al. 2002).

\subsubsection{Iwateken-Nairiku-Hokubu Earthquake M6.1 EQ1998/09/03}

In this section, we will present an example of the observed data relating to the Iwateken Nairiku-Hokubu EQ that occurred in the vicinity of Mt. Iwate in the northern part of Honshu

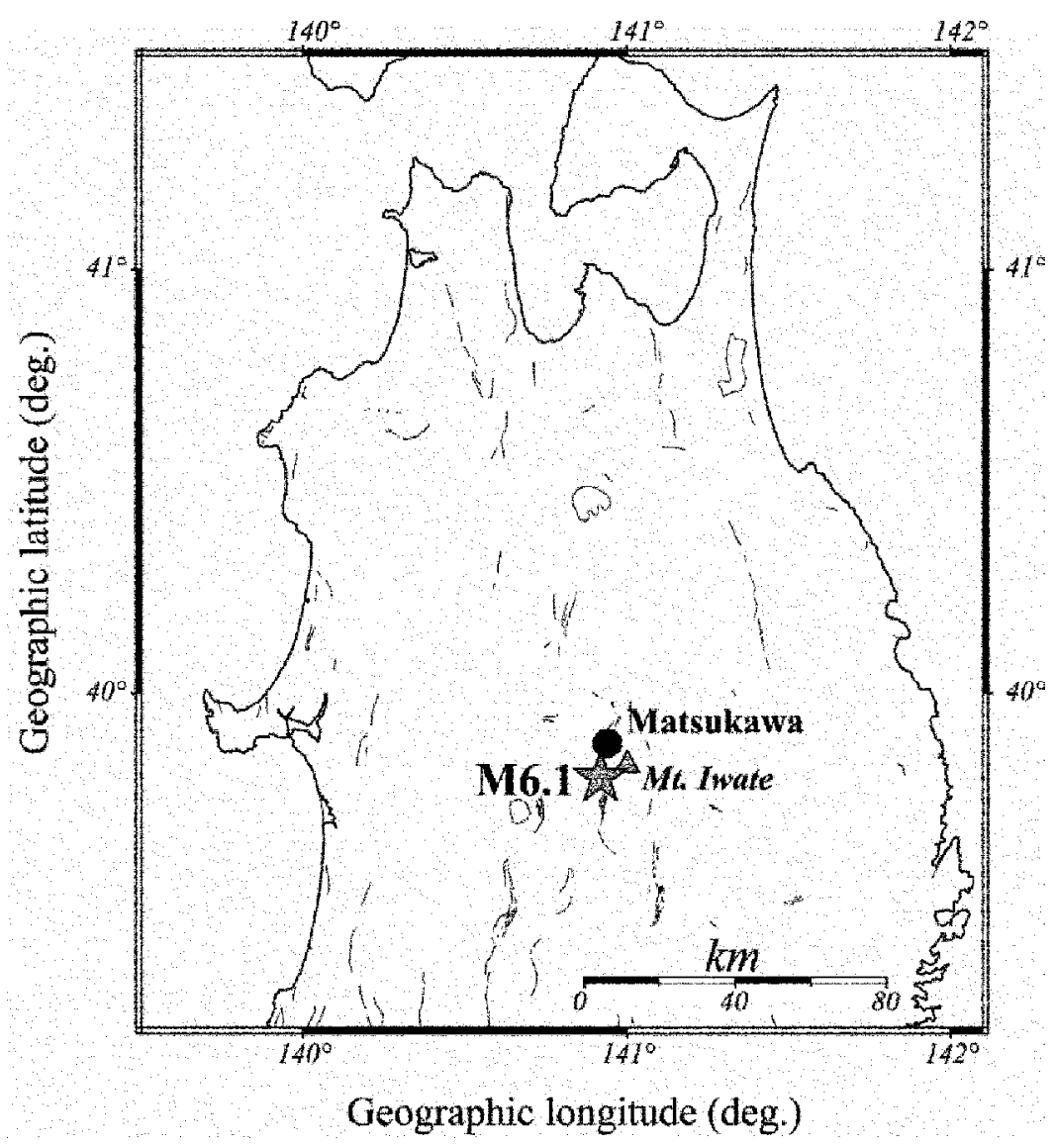

Fig. 9. The relative location between the epicenter of the 1998 IwatekenNairikuhokubu earthquake and Matsukawa station. 
Island ( $\mathrm{M}=6.1$, Depth $\sim 10 \mathrm{~km}, 3$ Sept., 1998). The epicentral distance from the Matsukawa station (MTK) was about $15 \mathrm{~km}$. Figure 9 shows the map. ULF magnetic phenomena associated with this earthquake were observed (Hattori et al. 2004a), as well as anomalous preseismic electric potential change (Uyeda et al. 2000) and co-seismic electric potential and magnetic field changes (Nagao et al. 2000). A five day running average of polarization $\left(S_{Z} / S_{H}\right.$ in $0.01 \mathrm{~Hz}$ band) showed an enhancement reaching three times higher than the usual value about two weeks before the EQ (Fig. 10). This happens to be about the same time that the Seismic Electric Signals (SES) were recorded.

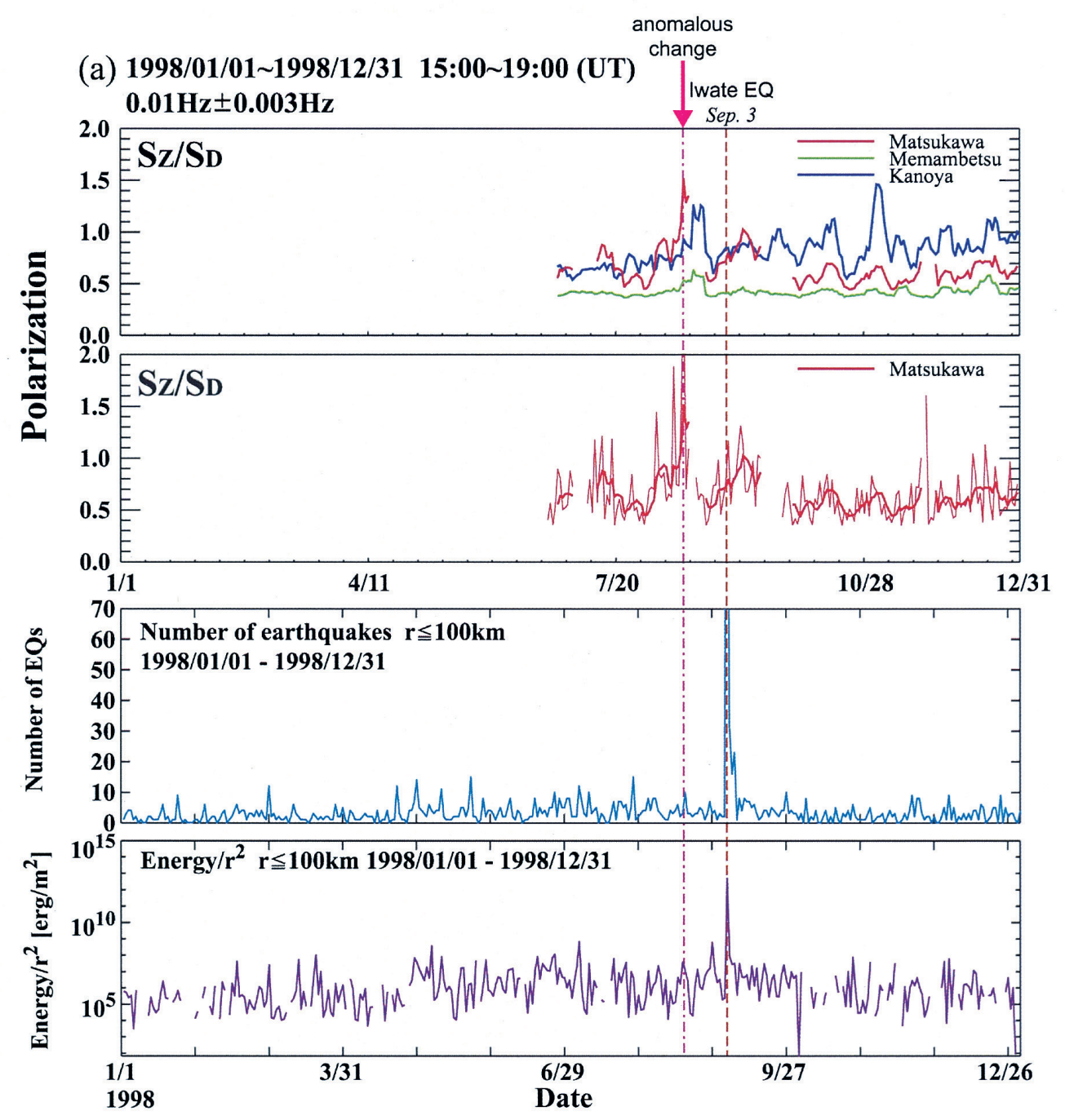


(b) 1999/01/01 1999/12/31 15:00 19:00 (UT)

$0.01 \mathrm{~Hz} \pm 0.003 \mathrm{~Hz}$

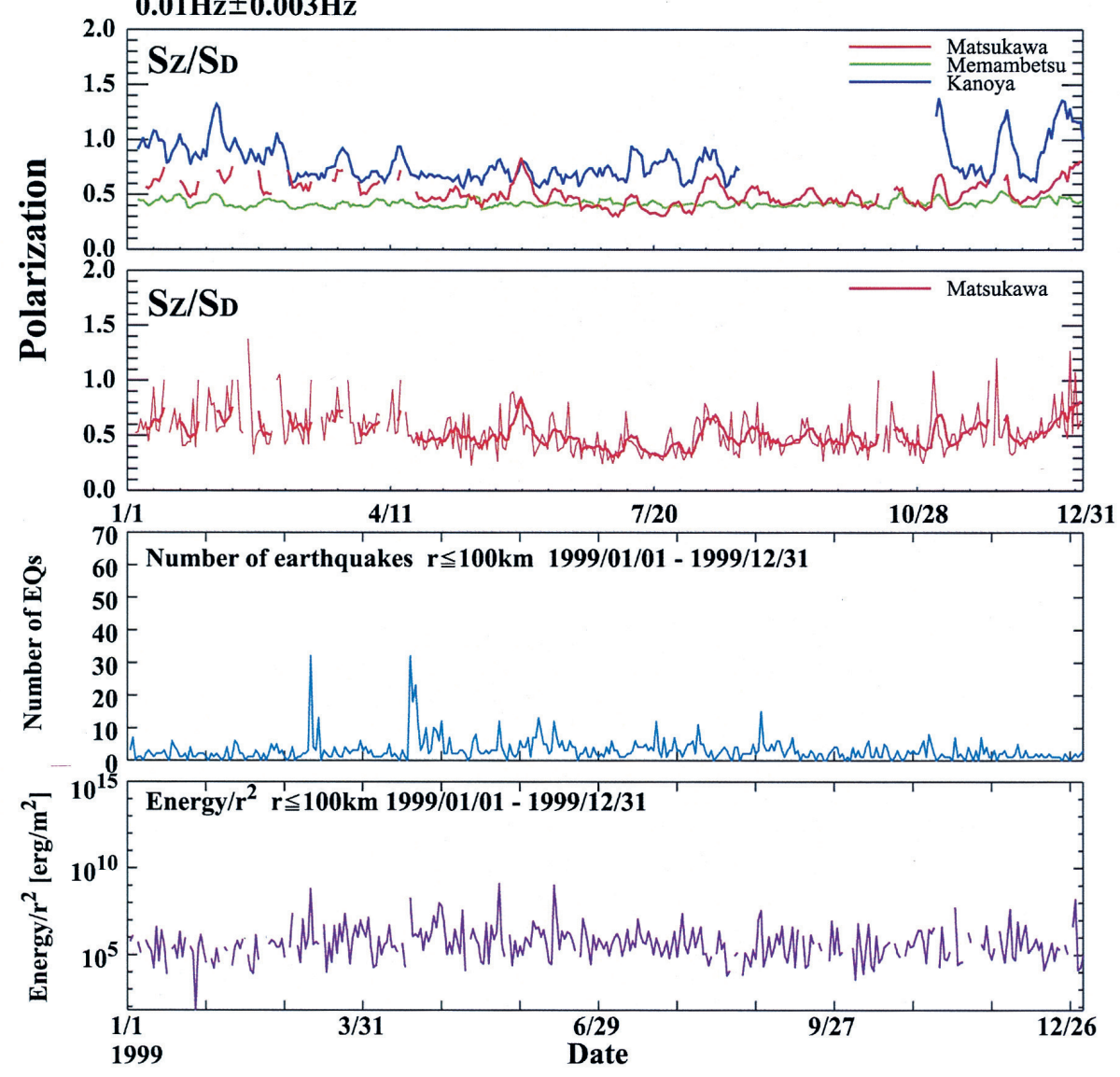

Fig. 10. The geomagnetic anomalous change associated with the IwatekenNairikuhokubu earthquake. The long-term variation of polarizations $\mathrm{S}_{\mathrm{Z}} / \mathrm{S}_{\mathrm{D}}$ at the frequency band of $0.01 \mathrm{~Hz}$ for five years is presented: (a) 1998 , (b) 1999. The top panel shows the variation of polarizations $S_{Z} / S_{D}$ at the frequency band of $0.01 \mathrm{~Hz}$. Five day backward running mean values at Matsukawa station (thick solid line) and at two remote reference stations, Memambetsu (thin solid line) and Kanoya (broken line) are simultaneously plotted. The second panel displays the detailed variation of polarization $S_{Z} / S_{D}$ at Matsukawa station. Five day backward running mean (thick solid line) and daily values (thin solid line) are plotted. The third panel shows the number of earthquake near Matsukawa station $(\mathrm{r}<$ $100 \mathrm{~km}$ ). The bottom panel indicates the variation of daily regional seismicity E/ $\mathrm{r}^{2}$, with taking account of hypocentral distance $\mathrm{r}$ (Hattori et al. 2004a). 

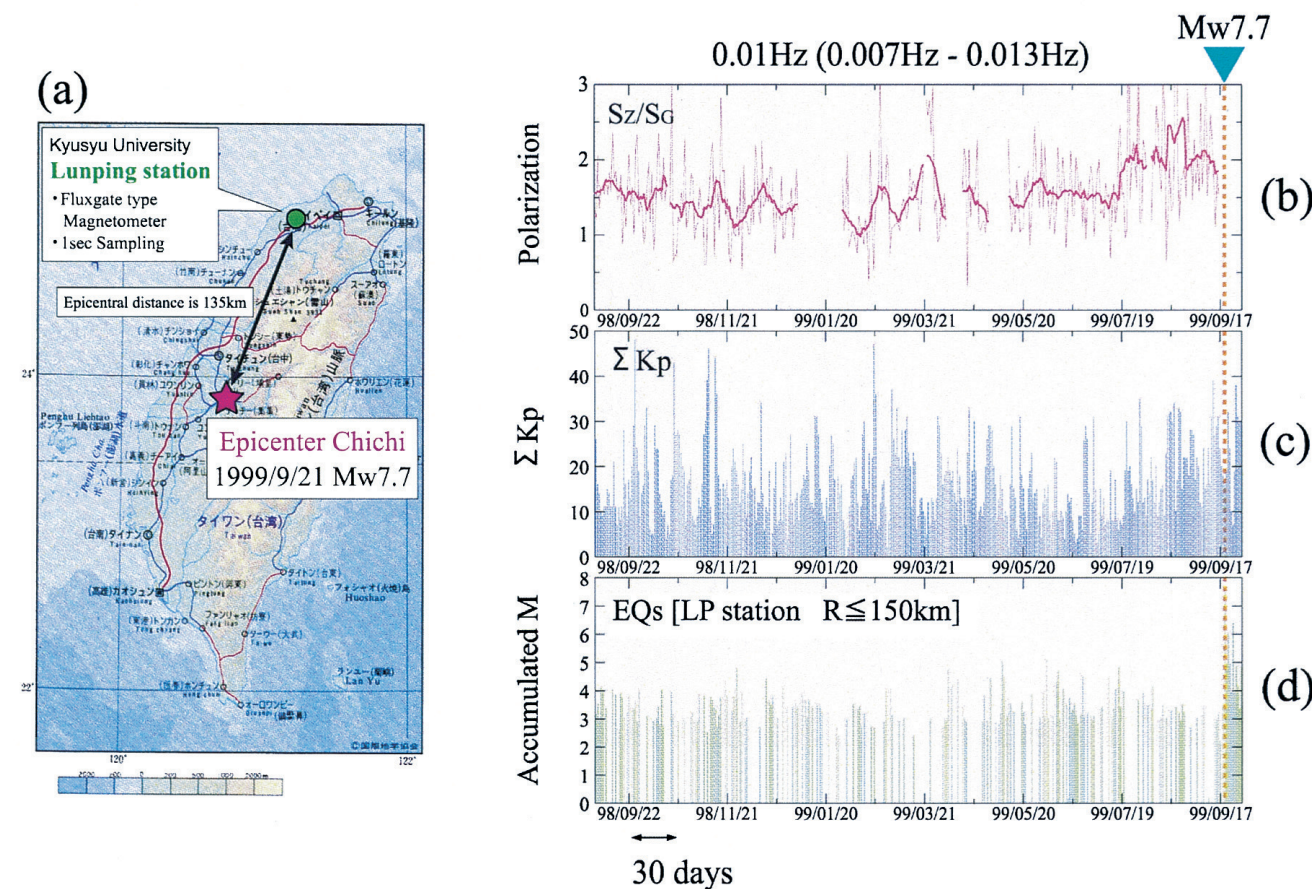

Fig. 11. The geomagnetic anomalous change associated with the 1999 Chi-Chi earthquake. The long-term variation of polarizations $S_{Z} / S_{D}$ at the frequency band of $0.01 \mathrm{~Hz}$ is presented: (a) The epicenter and the station, (b) The variation of polarizations $S_{Z} / S_{D}$ at the frequency band of 0.01 $\mathrm{Hz}$, (c) The variation of $\sum \mathrm{Kp}$, (d) Regional daily sum of seismicity in terms of magnitude.

\subsubsection{Chi-Chi Earthquake M6.1 EQ1999/09/21}

ULF geomagnetic data associated with the 1999 Chi-Chi EQ (M7.6) in Taiwan is investigated. The epicentral distance is about $135 \mathrm{~km}$ and a three-component magnetometer was in operation. Polarization analysis was carried out and it exhibited a significant enhancement about two months before the EQ (Akinaga et al. 2001, see Fig. 11).

\subsubsection{Biak Earthquake M8.2 EQ1996/02/17}

Polarization analysis associated with the 1996 Biak EQ (M 8.2), Indonesia is investigated (Hayakawa et al. 2000). The result shows that the enhancement of polarization occurred about one month prior to the EQ. 


\subsection{Principal Component Analysis of the 2000 Izu Volcanic-Seismic Activity in the Izu Island Region}

Swarm seismic activity started on June 26,2000 , simultaneously with volcanic activity at Miyake-jima Island. It quickly spread northwestward from the Miyake-jima Island to Toshima Island via Kozu-shima and Niijima Islands. Within the three month period of activity, more than 10,000 earthquakes ( $M>0$ ), including five events with $M \geq 6$, were recorded (Fig. 12).

Three-component geomagnetic monitoring was conducted by the array networks in west Izu Peninsula and south Boso Peninsula, each array consisting of three closely spaced ( 5 $\mathrm{km}$ ) stations with identical sensors (Fig. 12). Principal component analysis (PCA) has been applied to the ULF geomagnetic data of the Izu Peninsula array (Gotoh et al. 2002, Hattori et al. 2004b).

The first principal component was found to be a signal originating from solar-terrestrial effects, whereas the second principal component represented local artificial noise. It was also found that the smallest third component in the local midnight data indicated an increase in the

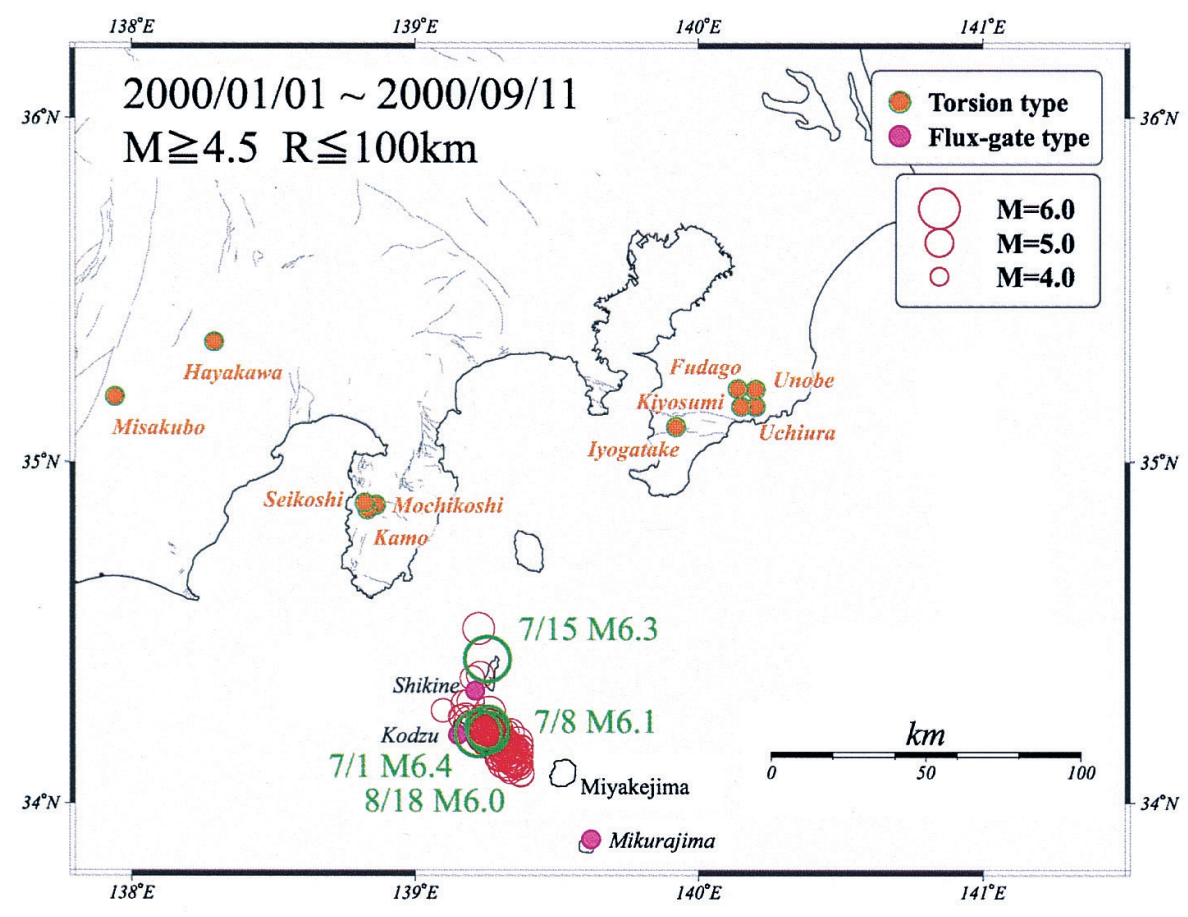

Fig. 12. ULF magnetometer array and the 2000 Izu Islands earthquake swarm. 


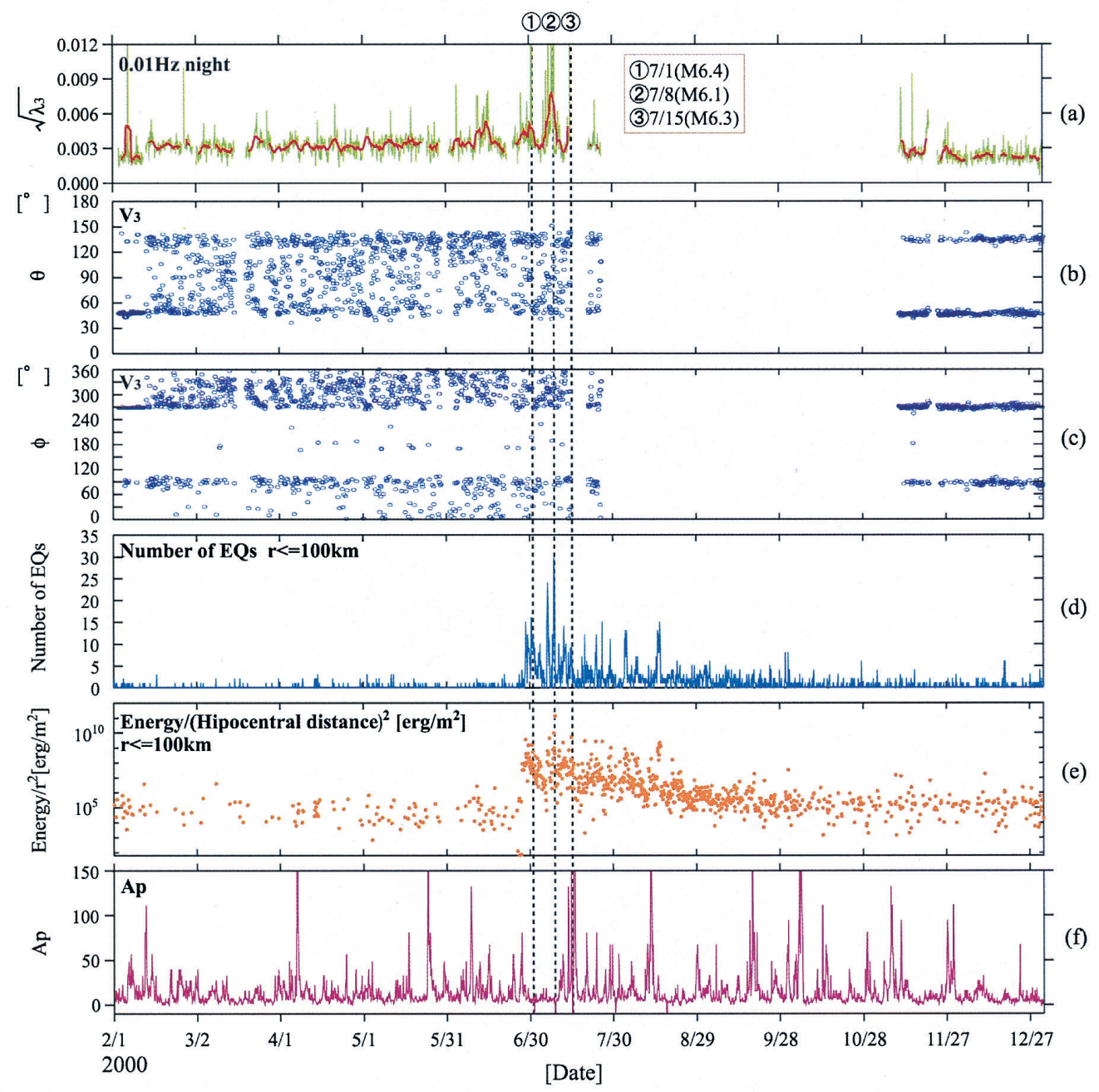

Fig. 13. The variation of third principal component $\sqrt{\lambda_{3}}$ in 2003. The occurrence time of a large earthquake $(M>6)$ is described by a vertical line. (a) the variation $\sqrt{\lambda_{3}}$ in midnight, (b) The variation of eigenvector $V_{3}$ in midnight; spherical coordinate system $(\mathrm{R}=1)$ is taken and $\phi$ values are plotted, (c) The variation of eigenvector $\mathrm{v} 3$ in midnight; spherical coordinate system $(\mathrm{R}=1)$ is taken and $\theta$ values are plotted, (d) the variation of number of earthquakes around the Izu array stations $(\mathrm{r}<100 \mathrm{~km})$, (e) the 30 minutes sum of the released energy $\left(\mathrm{E} / \mathrm{r}^{2}\right)$ around the Izu array station $(\mathrm{r}$ $<100 \mathrm{~km}$ ), (f) The variation of Kp index. The hypocentral distance $r$ is taken into account (after Hattori et al. 2004b). 
eigenvalue a few days before the large earthquakes (Earthquake M6.4 EQ2000/07/01, Earthquake M6.1 EQ2000/07/09, and Earthquake M6.3 EQ2000/07/15). Also about three months before the beginning of the swarm activity, the level of the third eigenvalue was slightly enhanced (Fig. 13). Correspondingly, the pattern of eigenvector direction in the signal subspace was changed simultaneously and recovered to the original state after the swarm (Hattori et al. 2004b). The corresponding electric field changes have been detected in the same frequency range (Uyeda et al. 2002).

\subsection{Direction Finding Analysis of the 2000 Izu Volcanic-Seismic Activity in the Izu Island Region}

Direction finding is an important analysis allowing for estimations in the direction of wave arrival. The direction finding used for ULF magnetic fields is based on the measurement of the magnetic fields observed at three stations in the small array as shown in Fig. 12 (Ismaguilov et al. 2001, 2003, Kopytenko et al. 2001, 2002a, b).

The result is illustrated in Fig. 14. The horizontal and vertical axes indicate the azimuth angle and the probability of wave arrival, respectively. The solid and broken lines correspond to the vertical and horizontal components at periods, respectively. The alphabetical order shows the time sequence and (d) indicates the active seismic period and (e) corresponds to the two years after the seismic active period. This figure shows that a few weeks before the swarm activity, the gradient-frequency response pattern of the vertical component apparently changed. That of the horizontal component shows that the additional signal source region appeared some months before the swarm activity and the possibility of signal reception is enhanced a few weeks before the activity. After the activity, the source region disappeared and the gradient-frequency pattern returned to normal. In contrast to the usual noise coming from the north (Izu Peninsula), the signals received in the summer of 2000, as in Figs. 14c, d, were coming from the direction of the swarm activity.

By using direction finding results from the arrays at Izu Peninsula and Boso Peninsula, the future focal region is found to be in the area of the cross-section of possible directions of wave arrival as shown in Fig. 15.

These results show that direction finding is of great significance in ULF magnetic studies preceding earthquakes.

\subsection{Fractal Analysis}

The use of the fractal analysis is based on the concept of self-organized criticality. The fractal analysis approach for ULF geomagnetic study was proposed for the 1993 Guam and the 1996 Biak earthquakes by Hayakawa et al. $(1999,2000)$. In their approach, the fractal dimension is estimated by using the slope of the power spectrum. Direct physical interpretation is not so easy but it seems useful in order to support or increase the reliability of the observational facts.

Quantitative methods for estimating the fractal dimension are proposed by Smirnova et al. (2001) and Gotoh et al. (2003). Gotoh et al. (2003) applied them to the ULF magnetic data 


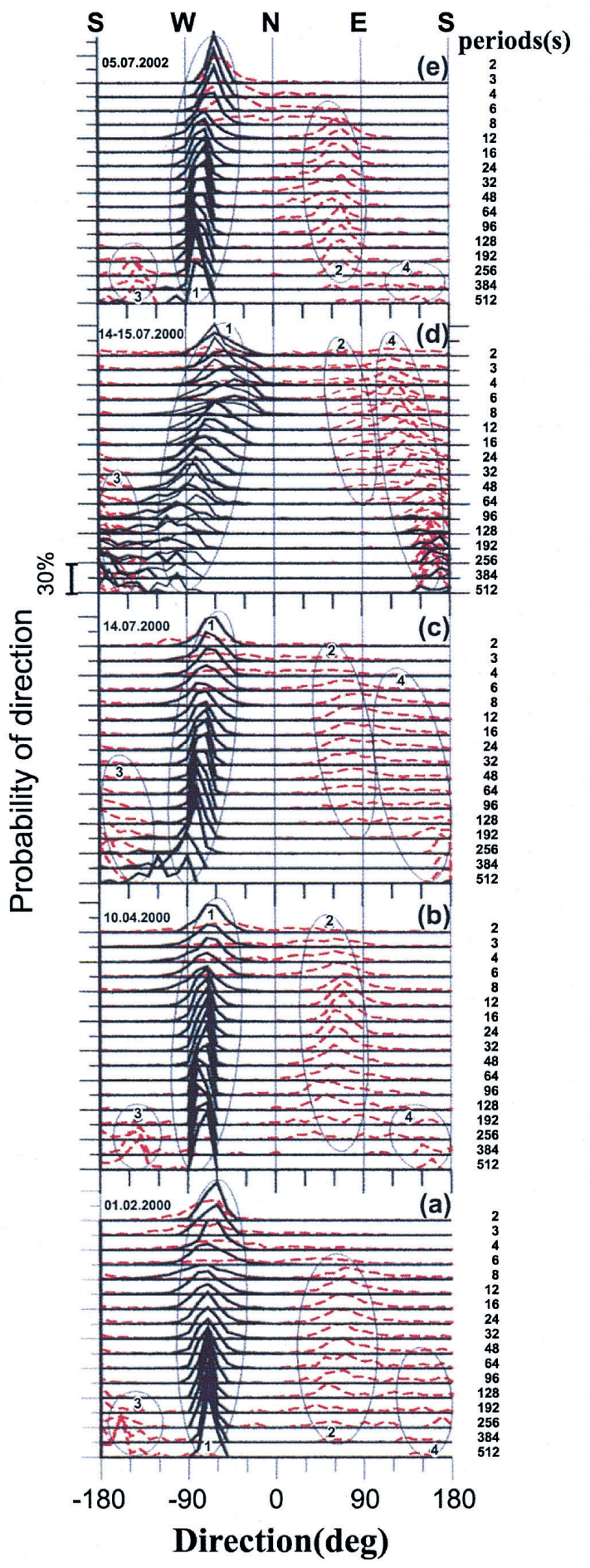

余宓

总方志

है을

空西

空

吾

号导

过

क 吾

西

$\Xi$ 吾

讨

8

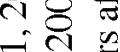

式

일

Q

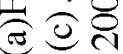

家的

产总

웡

:

흥

용

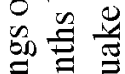

吾

C

효

记

$\exists \hat{\Xi}$

항

氞宗兵

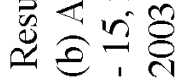

$\pm$

$\dot{0}$

Direction(deg) 


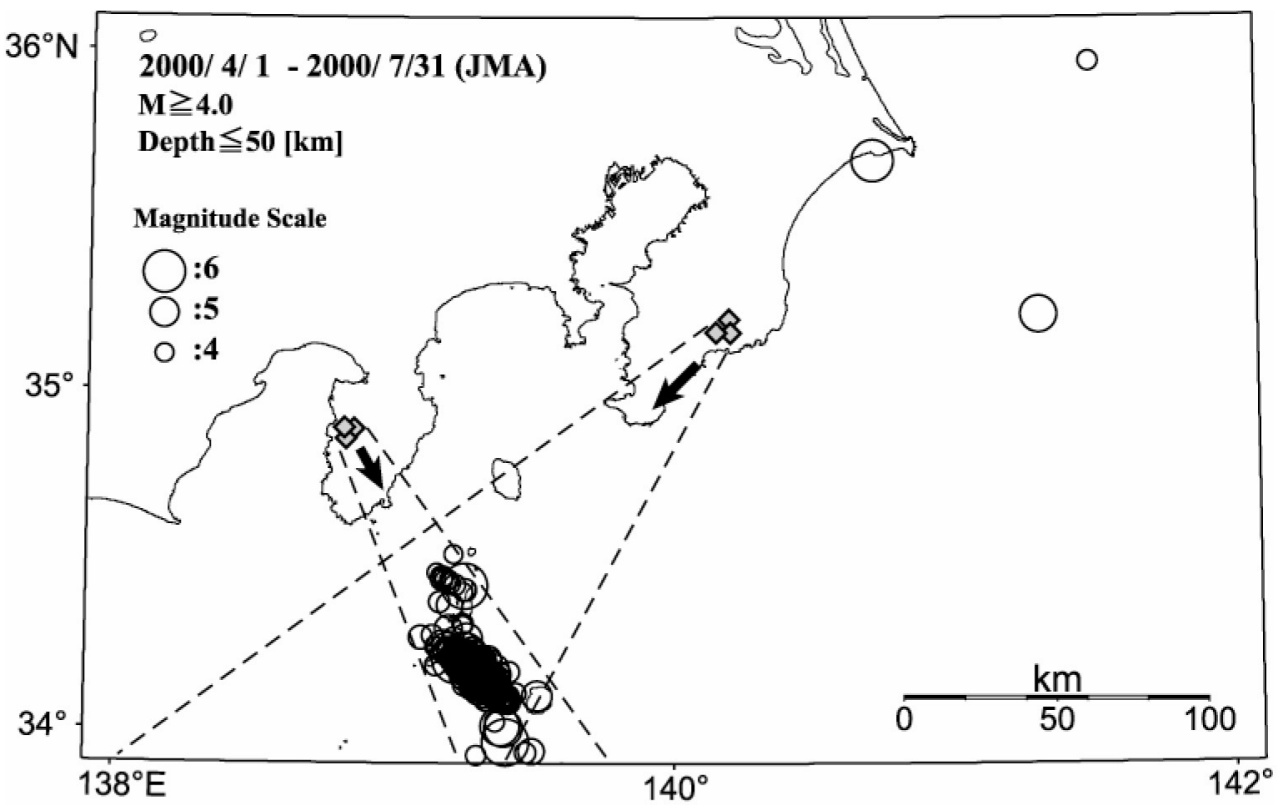

Fig. 15. Direction finding result using Izu and Boso arrays.

associated with the 2000 Izu Islands earthquake swarm. Gotoh et al. (2003) suggested that the Higuchi method was the best way to estimate the fractal dimension.

\section{SUMMARY OF ULF GEOMAGNETIC EMISSIONS PRECEDING LARGE EARTHQUAKES}

In this section, recent results based on the ULF emission concept, which are mainly from Japan's RIKEN and NASDA's Frontier Project, are summarized.

(1) Practical basis for a regular ground ULF electromagnetic field monitoring system has been established in Japan. It consists of the Kanto-Tokai network composed of sensitive sensors with high sampling rates and intersensor distances of $5 \mathrm{~km}, 20 \mathrm{~km}$, and $100 \mathrm{~km}$.

(2) ULF magnetic data associated with earthquakes have been analyzed with fairly sophisti cated signal processing procedures. Convincing results on the existence of anomalous ULF magnetic changes have been obtained for several earthquakes such as the KagoshimakenHokuseibu EQs, the Iwateken-Nairiku-Hokubu EQ, the Izu EQ swarm, the Biak EQ, the ChiChi EQ, and the Izu Island EQ swarm.

- $0.01 \mathrm{~Hz}$ band is effective for crustal monitoring.

- Enhancement of polarization (intensity ratio of vertical and horizontal components) starts a few weeks preceding the main shock.

- A tendency for increased horizontal components exists just before an earthquake. 
(3) Principal component analysis has been adopted to the horizontal component data observed at the Izu array network with intersensor distance of $5 \mathrm{~km}$.

- A few days before $M>6$ earthquakes, anomalous behavior was detected in the smallest eigenvalue $\sqrt{\lambda_{3}}$ during the Izu earthquake swarm in 2000.

- Slight increase at $\sqrt{\lambda_{3}}$ from mid-February 2000.

- Pattern of eigenvector at the period of enhanced $\sqrt{\lambda_{3}}$ is different from that of no en hancement of $\sqrt{\lambda_{3}}$.

(4) Gradient analysis is effective for direction finding. A few weeks before the swarm activity, the gradient-frequency response pattern of the vertical component is changed. That of the horizontal component shows an additional signal source region some months before the swarm activity and the possibility of signal reception is enhanced a few weeks before the activity. After the activity, the source region disappears and the gradient-frequency pattern returns to normal.

(5) ULF emissions can be detected, according to the experimental results obtained so far (including not only RIKEN/NASDA's but also others' results), when the condition $0.025 \mathrm{R}<\mathrm{M}-4.5$ is satisfied, where $\mathrm{M}$ is magnitude of the EQ and $\mathrm{R}$ is epicentral distance (See Fig. 16). During RIEKN/NASDA's study period, there have been 6 EQs which were reasonably expected to show pre-seismic signatures. Out of these, 5 EQs actually showed the signatures. These earthquakes and results are shown in Table 3.

Table.3. List of earthquakes with the anomalous behavior in ULF geomagnetic fields (polarization), when RIKEN/NASDA's network system was in operation and its results. The earthquakes satisfied $0.025 \mathrm{R}<\mathrm{M}-4.5$ are collected. (including Kagoshimaken-Hokuseibu EQ).

\begin{tabular}{|c|c|c|c|}
\hline Magnitude Day of EQ & $\begin{array}{l}\text { Distanc } \\
\text { e }\end{array}$ & Depth & Appearance of anomaly \\
\hline \multicolumn{4}{|l|}{ Matsukawa Station (June 1998 - ) } \\
\hline M6.1 EQ19980903(Iwateken-Nairikuhokubu EQ) & $15 \mathrm{~km}$ & $10 \mathrm{~km}$ & ( \\
\hline \multicolumn{4}{|l|}{ Boso stations (Feb. 2000-) } \\
\hline M5.8EQ20030920 & $72 \mathrm{~km}$ & $70 \mathrm{~km}$ & (O) \\
\hline \multicolumn{4}{|c|}{ Izu stations ( Temporary measurement in 1998-1999, Feb. 2000- ) } \\
\hline M5.7EQ19980503(Izu Swarm EQ) & $25 \mathrm{~km}$ & $20 \mathrm{~km}$ & (Q) \\
\hline M6.3EQ20000715(Izu Islands Swarm EQ) & $70 \mathrm{~km}$ & $10 \mathrm{~km}$ & $O$ (PCA, DF, Fractal) \\
\hline \multicolumn{4}{|l|}{ Kagoshima station (Nagoya Univ., ) } \\
\hline M6.5EQ19970326 (Kagoshimaken-Hokuseibu EQ) & $65 \mathrm{~km}$ & $20 \mathrm{~km}$ & (O) \\
\hline M6.3EQ19970513 (Kagoshimaken-Hokuseibu EQ) & $65 \mathrm{~km}$ & $20 \mathrm{~km}$ & 0 \\
\hline
\end{tabular}




\section{POSSIBLE PHYSICAL MECHANISM}

The origin of ULF electromagnetic field changes associated with EQs has been theoretically investigated by several scientists. Although presented models seem to explain some specific aspects of the ULF observations, no complete theory is so far available. There are at least three mechanisms which have been proposed for the generation of earth currents as sources of ULF emissions: (1) Electrokinetic effects (e.g., Mizutani and Ishido, 1976; Mizutani et al. 1976; Fitterman 1978, 1979, 1981; Ishido and Mizutani 1981; Dobrovolsky et al. 1989; Fenoglio et al. 1995), (2) Induction effects (Draganov et al. 1991; Surkov 1999), and (3) Microfracturing effects (Molchanov and Hayakawa 1995, 1998).

Fenoglio et al. (1995) tried to explain the ULF geomagnetic properties associated with the 1989 Loma Prieta earthquake by electrokinetic effects. They determined the electrical and magnetic fields generated during the failure of faults contained sealed compartments with pore pressures ranging from hydrostatic to lithostatic levels. They showed that electrokinetic effects due to water flow from high-pressure compartments to low-pressure areas are several orders of magnitude larger than the piezomagnetic and induction mechanisms. Further, they suggested that stop-and-start fracture propagation, a consequence of the spatial distribution of the pore pressure within the shear fracture, may explain the short-period ULF signals recorded prior to the M 7.1 Loma Prieta EQ.

If the intermittent movement or percolation of ionized underground water is generated, it is possible to explain anomalous behavior like ULF magnetic emissions. Simultaneous measurement with both magnetic and electrical fields could provide evidence for this mechanism.

The induction model explains ULF emissions as caused by electrical currents induced by conductive material in the geomagnetic field. Draganov et al. (1991) conducted a numerical calculation on the induction model to explain ULF magnetic fluctuations prior to the Loma Prieta EQ. They concluded that the observed magnetic fluctuations may occur due to the motion of ground water within the crust. Surkov and Pilipenko (1999), however, pointed out that the rock permeability required to explain the observation by the Draganov et al. model amounts to $10^{10} \mathrm{~m}^{2}$, which is about four orders of magnitude too high even for sands.

The microfracturing mechanism was proposed by Molchanov and Hayakawa $(1995,1998)$. The charge separation at opening micro-cracks and the radiation of electromagnetic waves from the generated micro-current in the future focal region could generate ULF emissions preceding the earthquakes. They considered the sum of current productions from many small micro-cracks, assuming that they tend to be aligned by large-scale stress-strain gradients. Each micro-current results from charge relaxation during micro-crack opening. But the alignment of micro-cracks should be adequate for polarity and coherency to generate currents large enough to cause ULF emissions.

Surkov (1999) investigated the possibility of the generation of EM perturbations due to electric currents during the micro-crack opening. The electric currents are assumed to be excited due to the crack-induced movements of the conductive medium in the geomagnetic field and generate magnetic pulses at separate micro-cracks. It was shown that coherent amplification of those magnetic pulses can occur under certain conditions. If this is true, it would be an extremely interesting phenomena. 
Surkov et al. (2002) also suggested that the acoustic wave radiated by tensile cracks results in the generation of extrinsic and electric currents in the conductive medium. The effective magnetic moment of extrinsic current is directed opposite to the vector of geomagnetic field induction independent on crack space orientation and attenuation factor. This makes micro-fields coherent in the ULF range. That is, the elastic wave controls the sign (coherency) of cracks for the electrical polarity.

Tzanis and Vallianatos (2002) proposed that the main source of the electrical current during fracturing is related to the motion of charged edge dislocations during crack formation and propagation in rocks under stress. The observable macroscopic ULF field can be generated by the superposition of multiple simultaneous tiny sources.

The propagation mechanism of ULF emissions is rather considerable because of their large skin depth. Molchanov et al. (1995) performed model calculations under the assumption of horizontal structure of underground conductivity and existence of ionosphere and estimated possible polarization at a remote site for the 1993 Guam EQ case.

Although there is uncertainty about the physical mechanism of ULF emissions associated with EQs, the current intensity for ULF sources was estimated by using the full-wave method and a simple Biot-Savart method. Molchanov et al. (1998) and Kawate et al. (1998) estimated the current source for the 1993 Guam EQ to explain the observed magnetic field. Hattori et al. (2002) tried to estimate the current density for the 1997 Kagoshimaken-Hokuseibu EQ with the use of the Biot-Savart approach.

\section{FUTURE DIRECTION OF THIS STUDY}

It is important to clarify the physical mechanism for ULF emissions associated with earthquakes. For this aim, the current number of observed ULF events is not enough, so that an accumulation of ULF events is very important. Applying various methods with multiple independent instruments for the same event or at the same time is a hopeful way to make results more convincing and to increase robustness of anomalous changes associated with earthquakes.

The intensity of ULF events is not so large and the distance between sensors and focal regions is usually not so close so that some sophisticated signal processing is essentially required such as polarization analysis, principal component analysis, direction finding analysis, and fractal analysis as described in this paper.

Further hopeful signal processing approaches can be suggested as follows. The multifractal analysis has been applied to self potential (electric potential difference) data and it seems to be a powerful tool to identify clusters at anomalous and ordinary stages (Telesca et al. 2004). This kind of multi-fractal approach should also be applied to ULF geomagnetic data. The caterpillar method or singular spectrum analysis, which is a kind of time series analysis of periodicity, and independent component analysis are also powerful techniques for signal discrimination (Troyan et al. 2002; Troyan and Hayakawa 2002).

It is also important to investigate the actual waveform of ULF emissions. For this aim, the development of intense noise reduction method is important. Harada et al. $(2003,2004)$ propose the noise reduction method for global signals, which are originated from solar-terrestrial 
interaction, using the remote reference station. A mathematical model for geomagnetic fields is also possible for detecting anomalous geomagnetic field changes. Alperovich et al. (2003) applied wavelet analysis to ULF geomagnetic data in order to detect earthquake-related signals. For artificial noise reduction, Liu (1999) and Koganeyama et al. (2003) tried to discriminate DC current driven train noise from magnetic data and electrical data, respectively.

From an observation viewpoint, some test fields like Park Field in the USA should be set up in seismically active regions such as Japan, Taiwan, Greece, Italy, Kamchatka, Middle Asia, Mexico, and so on. Simultaneous independent measurements not only in ULF signals but also on any electromagnetic and seismological changes should be carried out under international collaboration. As to the ULF measurements, measurements of 2 electric and 3 magnetic components with a high sampling rate $(<1 \mathrm{~Hz})$ and high resolution $(<1 \mathrm{pT})$ are required. Reference stations in aseismic and quiet regions should be used.

\section{CONCLUSION}

Although the number of ULF events is still limited, convincing cases of ULF geomagnetic anomalies associated with EQs are increasing gradually by means of sophisticated signal processing methodologies. Polarization analysis seems to be a similar approach to the conventional transfer function analysis in Conduction Anomaly (CA) study. CA is based on the investigation on the electrical properties under the ground and its variation, while polarization analysis is based on the concept of electromagnetic radiation originating from the current driven by electrification at the moment of microfracturing and by the movement or percolation of underground water in a future focal region.

It is essentially difficult to estimate transfer functions accurately with a conventional FFT approach when the external magnetic fields are not strong enough. Recently, simultaneous use of wavelet transform and reference data (interstation transfer function) have been effective in getting around these difficulties (Harada et al. 2003, 2004). A sensitive ULF geomagnetic network is now in operation over Kanto-Tokai area in Japan. Polarization analysis can be conducted with the wavelet transform as used in transfer function estimation. An inter-station transfer function approach can identify the magnetic variations originating from the solarterrestrial interaction. Therefore, it is possible to remove the global solar effects of magnetic pulsations in the ULF range. This will provide the means to differentiate the conductivity change and ULF emissions. It is noted that a reference station should be located in a seismically inactive region with a low artificial noise environment.

It is possible to apply polarization analysis to any three-component magnetometer record. Polarization analysis is a simple methodology but multiple-station analysis is required. Only single station analysis is not adequate because the appearance of anomalous changes in the vertical spectrum depends on the relative location of the station and the current source in the focal region. One of the multiple stations is selected as a reference station in a distant, seismically inactive area or at the geomagnetic conjugate point.

Morphological features of ULF emissions associated with large EQs are empirically summarized: (1) ULF emissions tend to appear only for large EQs (probably M > 5.5). (2) The 


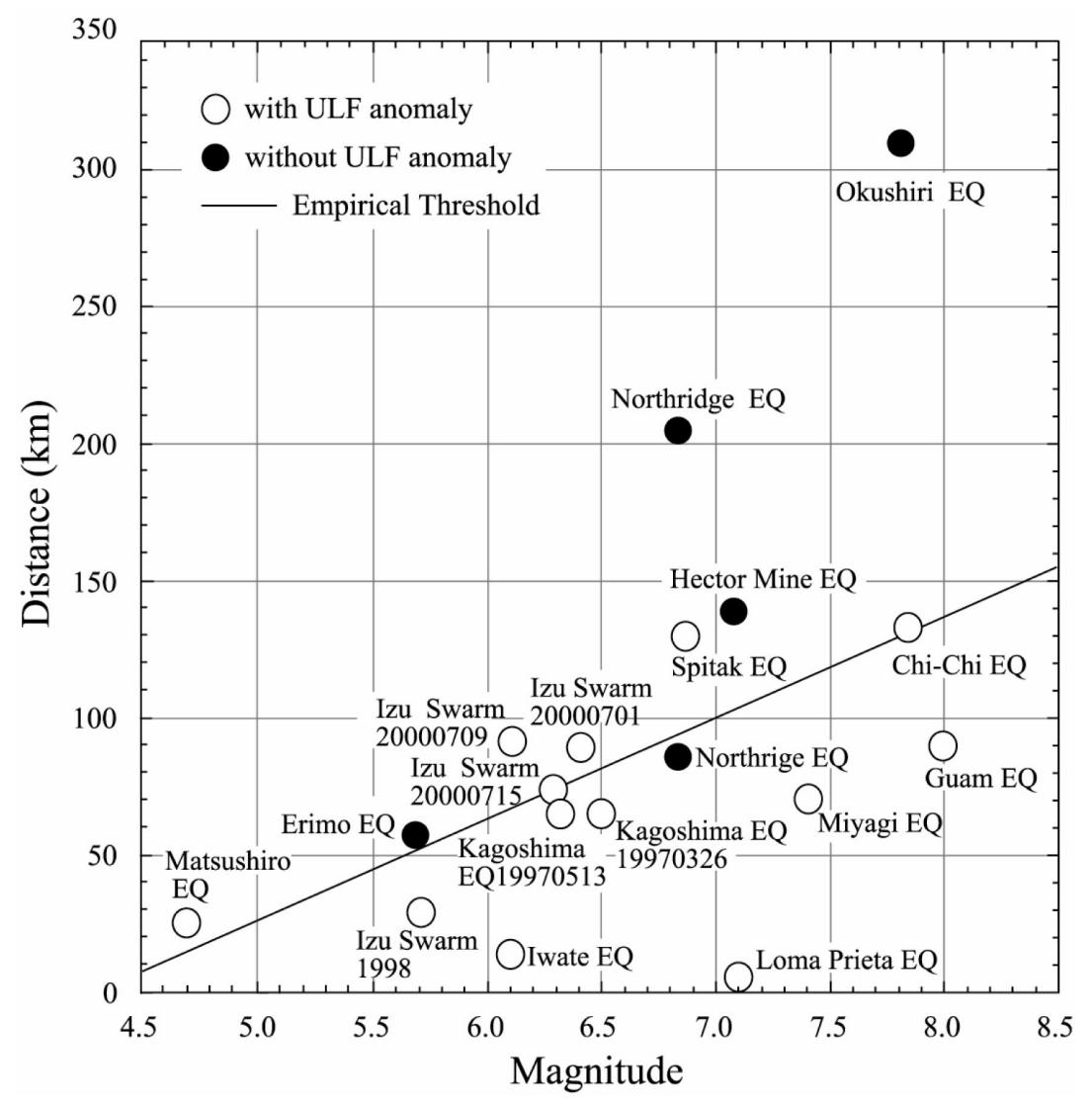

Fig. 16. Relation between magnitude and epicentral distance. $\mathrm{O}$ indicates the earthquake with the ULF anomaly, and $\bullet$ without the ULF anomaly.

intensity is not so large and the most useful frequency is just around $0.01 \mathrm{~Hz}$ (period $=100$ sec). (3) The typical time dependence of polarization and other indicators are as follows; the first enhancement or peak appears about one week to one month before the EQ, and then their level once again calms down. Then EQ occurs. (4) Fig. 16 is the global summary of the investigation on the pre-seismic ULF magnetic changes, showing the empirical relationship between M of EQ and epicentral distance of ULF stations. Pre-seismic ULF emissions would be detected for $\mathrm{M}>4.5 \mathrm{EQs}$ which roughly satisfy $0.025 \mathrm{R}<\mathrm{M}-4.5$, where $\mathrm{R}$ is epicentral distance (Uyeda 2003; Hattori et al. 2004a).

Acknowledgements I would like to thank my many colleagues for stimulating discussions and express special thanks to Institute of Physical and Chemical Research (RIKEN) and National Space Development Agency of Japan (NASDA) for supporting the special project of RIKEN International Frontier Research Group on Earthquake (1997 - 2002) and NASDA's Earthquake Remote Sensing Frontier Research (1997 - 2001). 


\section{REFERENCES}

Akinaga, Y., M. Hayakawa, J. Y. Liu , K. Yumoto, and K. Hattori, 2001: A precursory signature for Chi-Chi earthquake in Taiwan. Natural Hazards and Earth System Sci., 1, 3336.

Alperovich, L., V. Zheludev, and M. Hayakawa, 2003: Use of wavelet analysis for detection of seismogenic ULF emissions. Radio Sci., 38, 6, 1093, doi:10.1029/2002RS002687.

Beamish, D., 1982: A geomagnetic precursor to the 1979 Carlisle earthquake. Geophys. J. R. Astr. Soc., 68, 531-543.

Bernardi, A., A. C. Fraser-Smith, P. R. McGill, and O. G. Villard, Jr., 1991: ULF magnetic field measurements near the epicenter of the Ms 7.1 Loma Prieta earthquake. Phys. Earth Planet. Inter., 68, 45-63.

Dobrovolsky, I. P., N. I. Gershenzon, and M. B. Gokhberg, 1981: Theory of electrokinetic effects occurring at the final stage in the preparation of a tectonic earthquake. Phys. Earth Planet. Inter., 57, 144-156.

Draganov, A. B., U. S. Inan, and Yu. N. Taranenko, 1991: ULF magnetic signatures at the earth surface due to ground water flow: A possible precursor to earthquakes. Geophys. Res. Lett., 18, 1127-1130.

Fenoglio, M. A., M. J. S. Johnston, and J. Byerlee, 1995: Magnetic and electric fields associated with changes in high pore pressure in falut zones - Application to the Loma Prieta ULF emissions. J. Geophys. Res., 100, 12951-12958.

Fitterman, D. V., 1978: Electrokinetic and magnetic anomalies associated with dilatant regions in a layered earth. J. Geophys. Res., 83, 5923-5928.

Fitterman, D. V., 1979: Theory of electrokinetic-magnetic anomalies in faulted half-space.J. Geophys. Res., 84, 6031-6040.

Fitterman, D. V., 1981: Correction to "Theory of electrokinetic-magnetic anomalies in faulted half-space", J. Geophys. Res., 86, 9585-9588.

Fraser-Smith, A. C., A. Bernardi, P. R. McGill, M. E. Ladd, R. A. Helliwell, and O. G. Villard, Jr, 1990: Low-frequency magnetic field measurements near the epicenter of the Ms 7.1 Loma Prieta earthquake. Geophys. Res. Lett., 17, 1465-1468.

Galperin, Y. I., and M. Hayakawa, 1996: On the magnetospheric effects of experimental explosions observed from AUREOL-3.J. Geomagn. Geoelectr., 48, 1241-1263.

Gokhberg, M. B., V. A. Morgounov, T. Yoshino, and I. Tomizawa, 1982: Experimental measurement of electromagnetic emissions possibly related to earthquakes in Japan. $J$. Geophys. Res., 87, 7824-7828.

Gotoh, K., Y. Akinaga, , M. Hayakawa, and K. Hattori, 2002: Principal component analysis of ULF geomagnetic data for Izu islands earthquakes in July 2000. J. Atmos. Electr., 22, 1-12.

Gotoh, K., M. Hayakawa, and N. Smirnova, 2003: Fractal analysis of the geomagnetic data obtained at Izu Peninsula, Japan in relation to the nearby the earthquake swarm of June-August 2000. Natural Hazards and Earth System Sci., 3, 229-236. 
Gladychev, V., L. Baransky, A. Schekotov, G. Fedorov, E. Pokhotelov, O. Andreevsky, S. Rozhnoi, A. Khabazin, G. Belyaev, A. Gorbatikov, E. Gordeev, V. Chevrov, V. Sinitsin, A. Gorbatikov, E. Gordeev, V. Chevrov, O. Molchanov, M. Hayakawa, S. Uyeda, T. Nagao, K. Hattori, and Y. Noda, 2002: Some preliminary results of seismo-electromagnetic research at complex geophysical observatory, Kamchatka. In: M. Hayakawa and O. Molchanov (Eds.), Seismo Electromagnetics: Lithosphere-Atmosphere-Ionosphere coupling. TERRAPUB, Tokyo, 421-432.

Gufeld I. L., G. Gusev, and O. Pokhhotelov, 1994: Is the prediction of earthquake date possibe by VLF radio wave monitoring method?. In: M. Hayakawa and Y. Fujinawa (Eds.), Electromagnetic Phenomena Related to Earthquake Prediction. TERRAPUB, Tokyo, 381-390.

Harada, M., K. Hattori, and N. Isezaki, 2003: Global signal classification of ULF geomagnetic field variations using interstation transfer function. Inst. Electr. Eng. Japan., FM, 123, 1159-1165 (in Japanese with English abstract).

Harada, M., K. Hattori, and N. Isezaki, 2004: Transfer function analysis approach for anomalous ULF geomagnetic field change detection. Phys. Chem. Earth, 29, 409-417.

Hattori, K., Y. Akinaga, M. Hayakawa, K. Yumoto, T. Nagao, and S. Uyeda, 2002: ULF magnetic anomaly preceding the 1997 Kagoshima Earthquakes. In: M. Hayakawa and O. Molchanov (Eds.), Seismo Electromagnetics: Lithosphere-Atmosphere -Ionosphere coupling. TERRAPUB, Tokyo, 19-28.

Hattori, K., I. Takahashi, C. Yoshino, T. Nagao, J. Y. Liu, and C. F. Shieh, 2002: ULF Geomagnetic and Geopotential Measurement at Chia-Yi, Taiwan.J. Atmos. Electr., 22, 217-222.

Hattori, K., I. Takahashi, C. Yoshino, N. Isezaki, H. Iwasaki, M. Harada, K. Kawabata, E. Kopytenko, Y. Kopytenko, P. Maltsev, V. Korepanov, O. Molchanov, M. Hayakawa, Y. Noda, T. Nagao, and S. Uyeda, 2004a: ULF geomagnetic field measurements in Japan and some recent results associated with Iwateken Nairiku Hokubu Earthquake in 1998. Phys. Chem. Earth, 29, 481-494.

Hattori, K., A. Serita, K. Kaoru Gotoh, C. Chie Yoshino, M. Harada, N. Isezaki, and M. Hayakawa, 2004b: ULF geomagnetic anomaly associated with 2000 Izu islands earthquake swarm, Japan. Phys. Chem. Earth, 29, 425-435.

Hayakawa, M. and Y. Fujinawa (Eds.), 1994: "Electromagnetic Phenomena Related to Earthquake Prediction". TERRAPUB, Tokyo, 677p.

Hayakawa, M., R. Kawate, O. A. Molchanov, and K. Yumoto, 1996a: Results of ultra-lowfrequency magnetic field measurements during the Guam earthquake of 8 August 1993. Geophys. Res. Lett., 23, 241-244.

Hayakawa, M., O. A. Molchanov, T. Ondoh, and E. Kawai, 1996b: Anomalies in the subionospheric VLF signals for the 1995 Hyogo-ken Nanbu earthquake.J. Phys. Earth, 44, 413-418.

Hayakawa, M. (Ed.), 1999: Atmospheric and Ionospheric Electromagnetic Phenomena Associated with Earthquakes. TERRAPUB, Tokyo, 996 p.

Hayakawa, M., T. Itoh, and N. Smirnova, 1999: Fractal analysis of ULF geomagnetic data associated with the Guam on August 8, 1993. Geophys. Res. Lett., 26, 2797-2800. 
Hayakawa, M., T. Itoh, K. Hattori, and K. Yumoto, 2000: ULF electromagnetic precursors for an earthquake at Biak, Indonesia on February 17, 1996. Geophys. Res. Lett., 27, 1531-1534.

Hayakawa, M., and O. A. Molchanov (Eds.), 2002: Seismo Electromagnetics LithosphereAtmosphere-Ionosphere Coupling. TERRAPUB, Tokyo, 477p.

Hayakawa, M., 2001: NASDA's Earthquake Remote Sensing Frontier Research: Seismoelectromagnetic Phenomena in the Lithosphere, Atmosphere and Ionosphere, Final Report. Univ. Electro-Comms., 228p.

Honkura, Y. and S. Koyama, 1978: Observation of short-period geomagnetic variations at Nakaizu. Bull. Earthq. Res. Inst., Univ. Tokyo, 53, 925-930 (in Japanese).

Honkura, Y., 1979: Observation of short-period geomagnetic variations at Nakaizu (2): Cahnges in transfer functions associated with the Izu-Ohshima-Kinkai earthquake of 1978. Bull. Earthq. Res. Inst., Univ. Tokyo, 54, 477-490.

Ishido, T. and H. Mizutani, 1981: Experimental and theoretical basis of electrokinetic phenomena to rock-water systems and its applications to geophysics.J. Geophys. Res., 86, 1763-1775.

Ismaguilov, V., Y. Kopytenko, K. Hattori, M. Voronov, O. Molchanov, and M. Hayakawa, 2001: ULF magnetic emissions connected with under sea bottom earthquakes. Natural Hazards and Earth System Sci., 1, 23-31.

Ismaguilov, V., Y. Kopytenko, K. Hattori, and M. Hayakawa, 2003: Variations of phase velocity and gradient values of ULF geomagnetic disturbances connected with the Izu strong earthquake. Natural Hazards and Earth System Sci., 3, 211-215.

Johnston, M., 1997: Review of electric and magnetic fields accompanying seismic and volcanic activity. Surveys in Geophys., 18, 441-475.

Kato, A., M. Seto, H. Saitoh, K. Yumoto, and T. Hayasaka, 1980: Geomagnetic variation associated with the 1978 Miyagiken-oki earthquake. The Earth Monthly, 2, 392-396 (in Japanese).

Kawate, R., O. A. Molchanov, and M. Hayakawa, 1998: Ultra-low-frequency magnetic fields during the Guam earthquake of 8 August 1993 and their interpretation. Phys. Earth Planet. Inter., 105, 229-238.

Koganeyama, M., S. Sawa, H. Shouno, T. Nagao, and K. Joe, 2003: An effective evaluation function for ICA to separate train noise from telluric current data, $4^{\text {th }}$ Int' 1 Symp. On Independent Component. Analysis and Blind Signal Separation, 867-872.

Kopytenko, Y. A., T. G. Matishvili, P. M. Voronov, E. A. Kopytenko, and O. A. Molchanov, 1990: Discovering of ultra-low-frequency emissions connected with Spitak earthquake and his aftershock activity on data of geomagnetic pulsations observations at Dusheti and Vardzija. IZMIRAN Preprint N3 (888), 27p., Moscow.

Kopytenko, Y. A., T. G. Matishvili, P. M. Voronov, E. A. Kopytenko, and Molchanov, O. A., 1993: Detection of ultra-low-frequency emissions connected with the Spitak earthquake and its aftershock activity, based on geomagnetic pulsations data at Dusheti and Vardzia observatories. Phys. Earth Planet. Inter., 77, 85-95. 
Kopytenko Y. A., T. G. Matishvili, P. M. Voronov, and E. A. Kopytenko, 1994: Observation of electromagnetic ultra-low-frequency lithospheric emissions in the Caucasian seismically active zone and their connection with earthquakes. In: M. Hayakawa and Y. Fujinawa (Eds.), Electromagnetic Phenomena Related to Earthquake Prediction, TERRAPUB, Tokyo, 175-180.

Kopytenko, Y., V. Ismaguilov, K. Hattori, P. Voronov, M. Hayakawa, O. Molchanov, E. Kopytenko, and D. Zaitsev, 2002a: Monitoring of the ULF electromagnetic disturbances at the station network before EQ in seismic zones of Izu and Chiba Peninsulas. In: M. Hayakawa and O. Molchanov (Eds.), Seismo Electromagnetics: LithosphereAtmosphere- Ionosphere coupling, TERRAPUB, Tokyo, 11-18.

Kopytenko, Y., V. Ismaguilov, O. Molchanov, E. Kopytenko, P. Voronov, K. Hattori, P. Voronov, M. Hayakawa, and D. Zaitsev, 2002b: Investigation of ULF magnetic disturbances in Japan during active seismic period. J. Atmos. Electr., 22, 207-215.

Lighthill, J., 1996: A critical review of VAN, World Scientific, Singapore, 376p.

Liu, T. T, 1999: Ultra-low frequency magnetic fields in the San Francisco Bay area: measurements, methods, and signal processing, Technical Report D180-2 (Ph.D Thesis of Stanford University), 190p.

Makris, J. P., F. Vallianatos, Y. Kopytenko, N. Smirnova, V. Korepanov, E. Kopytenko, P. Soupios, I. Vardiambasis, A. Stampolidis, and A. Mavromatidis, 2003: ULF Geomagnetic Observations and Seismic Activity on the Southern Part of Hellenic Arc, Geophysical Research Abstracts 5(EGS-AGU-EUG Joint Assembly, 06-11 April 2003, Nice, France), 12338 (CDROM)

Mizutani, H. and T. Ishido, 1976: A new interpretation of magnetic field variation associated with Matsushiro earthquakes. J. Geomag. Geoelectr., 28, 179-188.

Mizutani, H., T. Ishida, T. Yokokura, and S. Ohnishi, 1976: Electrokinetic phenomena associated with earthquakes. Gophys. Res. Lett., 3, 365-368.

Molchanov, O. A., Y. A. Kopytenko, P. M. Voronov, E. A. Kopytenko, T. G. Matiashvili, A. C. Fraser-Smith, and A. Bernardi, 1992: Results of ULF magnetic field measurements near the epicenters of the Spitak $(\mathrm{Ms}=6.9)$ and Loma Prieta $(\mathrm{Ms}=7.1)$ earthquakes: Comparative analysis. Geophys. Res. Lett., 19, 1495-1498.

Molchanov, O. A., M. Hayakawa, and V. A. Rafalsky, 1995: Penetration characteristics of electromagnetic emissions from an underground seismic source into the atmosphere, ionosphere, and magnetosphere. J. Geophys. Res., 100, 1691-1712.

Molchanov, O. A., and M. Hayakawa, 1995: Generation of ULF electromagnetic emissions by microfracturing. Geophys. Res. Lett., 22, 3091-3094.

Molchanov, O. A., and M. Hayakawa, 1998a: On the generation mechanism of ULF seismogenic emissions. Phys. Earth Planet. Inter., 105, 201-210.

Molchanov, O. A., and M. Hayakawa, 1998b: Subionospheric VLF signal perturbations possibly related to earthquakes. J. Geophys. Res., 103, 17489-17504.

Nagao, T., Y. Orihara, T. Yamaguchi, I. Takahashi, K. Hattori, Y. Noda, K. Sayanagi, and Uyeda, S., 2000: Co-seismic geoelectric potential changes observed in Japan. Geophys. Res. Lett., 27, 1535-1538. 
Parrot, M., Statistical studies with satellite observation of seismogenic effects, 1999. In: M. Hayakawa (Ed.), Atomospheric and Ionospheric Electromagnetic Phenomena Associated with Earthquakes, TERRAPUB, Tokyo, 685-695.

Rikitake, T. and Y. Honkura, , 1985: Solid earth geomagnetism, Terra Sci. Pub., 384p.

Schmucker, U., 1970: Anomalies of geomagnetic variations in the southern United States. Bull. Scripps Inst. Oceanogr., 13, 165p., Univ. California Press.

Scholz, C. H., L. R. Sykes, and Y. P. Aggarwal, 1973: Earthquake prediction: a physical basis. Science, 181, 803-810.

Shiraki, M., 1980: Monitoring the time change in transfer functions in the central Japan conductivity anomaly. J. Geomag. Geoelectr., 32, 637-648.

Smirnova, N., M. Hayakawa, K. Gotoh, and D. Volobuev, 2001: Scaling characteristics of ULF geomagnetic field at the Guam seismoactive area and their dynamics in relation to the earthquake. Natural Hazards and Earth System Sci., 1, 119-126.

Surkov, V. V., 1999: ULF electromagnetic perturbations resulting from the fracture and dilatancy in the earthquake preparation zone. In: M. Hayakawa (Ed.), Atomospheric and Ionospheric Electromagnetic Phenomena Associated with Eathquakes, TERRAPUB, Tokyo, 371-382.

Surkov, V. V., O. A. Molchanov, and M. Hayakawa, 2003: Pre-earthquake ULF electromagnetic perturbations as a result of inductive seismogenic phenomena during microfracturing. J. Atmos. Solar-Terr. Phys., 65, 31-46.

Surkov, V. V. and V. Pulipenko, 1999: The physics of pre-seismic ULF signals. In: M. Hayakawa (Ed.), Atomospheric and Ionospheric Electromagnetic Phenomena Associated with Eathquakes, TERRAPUB, Tokyo, 357-370.

Telesca, L., V. Lapenna, , and F. Vallianatos, , 2002: Monofractal and multifractal approaches in investigating scaling properties in temporal patterns of the 1983-2000 seismicity in the western Corinth graben, Greece. Phys. Earth Planet. Int., 131, 63-79.

Troyan, V. N. and M. Hayakawa, 2002: Methods for geophysical data processing in seismic active zones. In: M. Hayakawa and O. Molchanov (Eds.), Seismo Electromagnetics: Lithosphere- Atmosphere-Ionosphere coupling, TERRAPUB, Tokyo, 215-221.

Troyan, V. N. and Hayakawa, 2003: Inverse geophysical problems. TERRAPUB, Tokyo, $289 \mathrm{p}$.

Tzanis, A. and F. Vallianatos, A physical model of electrical earthquake precursors due to crack propagation and the motion of charged edge dislocations, 2002. In: M. Hayakawa and O. Molchanov (Eds.), Seismo Electromagnetics: Lithosphere-Atmosphere -Ionosphere coupling, TERRAPUB, Tokyo, 117-130.

Uyeda, S., T. Nagao, Y. Orihara, T. Yamaguchi, and I. Takahashi, 2000: Geoelectric potential changes: Possible precursors to earthquakes in Japan. Proc. US Nat'l Acd. Sci., 97, 4561-4566.

Uyeda, S., T. Nagao, K. Hattori, , Y. Noda, M. Hayakawa, K. Miyaki, O. Molchanov, V. Gladychev, L. Baransky, A. Schekotov, G. Belyaev, E. Fedorov, O. Pokhotelov, S. Andreevsky, A. Rozhnoi, Y. Khabazin, A. Gorbatikov, E. Gordeev, V. Chevrov, A. Lutikov, S. Yunga, G. Kasarev, and V. Surkov, 2002: Russian-Japanese complex geophysical observatory in Kamchatka for monitoring of phenomena connected with seismic activity, In: M. Hayakawa and O. Molchanov (Eds.), Seismo Electromagnetics: Lithosphere-Atmosphere -Ionosphere coupling, TERRAPUB, Tokyo, 413-420. 
Uyeda, S., M. Hayakawa, T. Nagao, O. Molchanov, K. Hattori, Y. Orihara, K. Gotoh, Y. Akinaga, and H. Tanaka, 2002: Electric and Magnetic phenomena observed before the volcano-seismic activity 2000 in the Izu islands region, Japan. Proc. US Nat'l Acd. Sci., 99, 7352-7355.

Uyeda, S., 2003: International Frontier Research Group on Earthquakes (IFREQ) Final Report, Tokai Univ., CD-ROM.

Yanagihara, K., 1972: Secular variation of the electrical conductivity anomaly in the central part of Japan. Memories Kakioka Magnetic Observatory, 15, 1-10.

Yanagihara, K. and T. Nagano, 1976: Time change of transfer function in the central Japan anomaly of conductivity with special reference to earthquake occurrences.J. Geomag. Geoelectr., 28, 157-163.

Yumoto., K., Y. Tanaka., T. Oguti, K. Shiokawa, Y. Yoshimura, A. Isono, B. J. Fraser, F. W. Menk, J. W. Lynn, M. Seto, and 210 MM Magnetic Observation Group, 1992: Globally coordinated magnetic observations along $210^{\circ}$ magnetic meridian during STEP period: 1. Preliminary results of low-1atitude Pc3's. J. Geomag. Geoelectr., 44, 261276.

Zlotnicki, J. and Y. Nisida, 2003: Review of morphological insights of self-potential anomalies on volcano. Surveys in Geophys., 24, 291-338. 